\title{
High Efficiency Syngas Generation
}

\section{Final Report}

\author{
By: \\ Robert J. Copeland \\ Yevgenia Gershanovich \\ Brian Windecker
}

TDA Research, Inc. 12345 W. 52nd Ave.

Wheat Ridge, CO 80033-1916

\author{
For: \\ National Energy Technology Laboratory \\ U.S. Department of Energy \\ 3610 Collins Ferry Road P.O. Box 880 \\ Morgantown, WV 26507-0880 \\ Contract No. FE-FC26-01NT41226 \\ Aaron Yocum, Project Officer
}

Period of Performance: Oct. 1, 2001 - Sept. 30, 2003

February 2005 


\section{Disclaimer}

This report was prepared as an account of work sponsored by an agency of the United States Government. Neither the United States Government nor any agency thereof, nor any of their employees, makes any warranty, express or implied, or assumes any legal liability or responsibility for the accuracy, completeness, or usefulness of any information, apparatus, product, or process disclosed, or represents that its use would not infringe privately owned rights. Reference herein to any specific commercial product, process, or service by trade name, trademark, manufacturer, or otherwise does not necessarily constitute or imply its endorsement, recommendation, or favoring by the United States Government or any agency thereof. The views and opinions of authors expressed herein do not necessarily state or reflect those of the United States Government or any agency thereof. 


\section{Abstract}

This project investigated an efficient and low cost method of auto-thermally reforming natural gas to hydrogen and carbon monoxide. Reforming is the highest cost step in producing products such as methanol and Fisher Tropsch liquids (i.e., gas to liquids); and reducing the cost of reforming is the key to reducing the cost of these products. Steam reforming is expensive because of the high cost of the high nickel alloy reforming tubes (i.e., indirectly fired reforming tubes). Conventional auto-thermal or Partial Oxidation (POX) reforming minimizes the size and cost of the reformers and provides a near optimum mixture of $\mathrm{CO}$ and hydrogen. However POX requires pure oxygen, which consumes power and significantly increases the cost to reforming. Our high efficiency process extracts oxygen from low-pressure air with novel oxygen sorbent and transfers the oxygen to a nickel-catalyzed reformer. The syngas is generated at process pressure (typically 20 to 40 bar) without nitrogen dilution and has a $1 \mathrm{CO}$ to $2 \mathrm{H}_{2}$ ratio that is near optimum for the subsequent production of Fisher-Tropsch liquid to liquids and other chemicals (i.e., Gas to Liquids, GTL). Our high process efficiency comes from the way we transfer the oxygen into the reformer. All of the components of the process, except for the oxygen sorbent, are commonly used in commercial practice. A process based on a longlived, regenerable, oxygen transfer sorbent could substantially reduce the cost of natural gas reforming to syngas. Lower cost syngas $\left(\mathrm{CO}+2 \mathrm{H}_{2}\right)$ that is the feedstock for GTL would reduce the cost of GTL and for other commercial applications (e.g., methanol, other organic chemicals). The vast gas resources of Alaska's North Slope (ANS) offer more than 22 Tcf of gas and GTL production in this application alone, and could account for as much as 300,000 to 700,000 bpd for 20 to 30+ years. We developed a new sorbent, which is an essential part of the High Efficiency Oxygen Process (HOP). We tested the sorbent and observed that it has both a good oxygen capacity and operates as a highly effective reforming catalyst. We conducted a long duration tests of the sorbent (1,500 hours of continuous operation in the HOP cycle). Although the sorbent lost some oxygen capacity with cycling, the sorbent oxygen capacity stabilized after 1,000 hours and remained constant to the end of the test, 1,500 hour. The activity of the catalyst to reform methane to a hydrogen and carbon monoxide mixture was unchanged through the oxidation/reduction cycling. Our cost and performance analyses indicated a significant reduction in the cost of GTL production when using the HOP process integrated into a GTL plant. 


\section{Acknowledgements}

Department of Energy (DOE), National Energy Technology Laboratory (NETL) provided financial assistant and technical support. Mr. Aaron Yocum [aaron.yocum@netl.doe.gov], the final NETL technical monitor, and Ms Jenny Tennant [JENNY.TENNANT@netl.doe.gov] the initial NETL technical monitor provided guidance and direction in the research; their assistance at several critical points is gratefully acknowledged.

TDA Research, Inc. (TDA) conducted this work with the support from Air Products and Chemicals, Inc. Allentown, PA (APCI). Dr. Shankar Nataraj, APCI Principal Process Engineer, [NATARAS@apci.com] and Mr. Blaine Herb, APCl Process Engineer, Herb, Blaine E. [HERBBE@apci.com] prepared the detail ASPEN model and the cost/performance analysis based on that model. 


\section{Table of Contents}

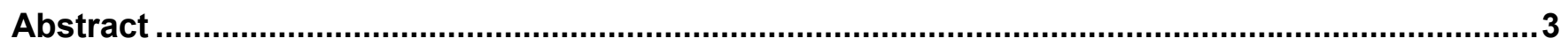

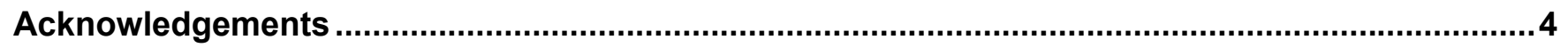

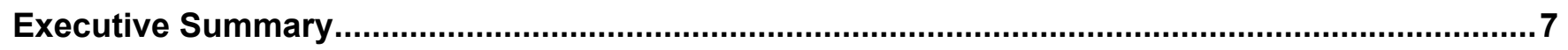

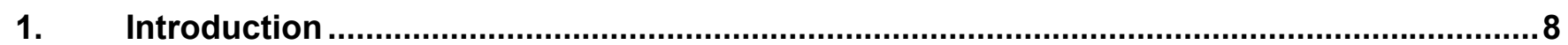

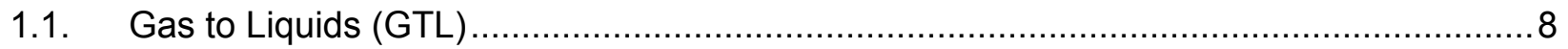

1.2. How the Proposed Work Will Result in Improvements Over Existing Technologies ....... 10

1.3. Potential for a Scientific or Engineering Breakthrough............................................ 11

1.4. The Scientific and Technical Basis and Merit of the High [efficiency] Oxygen Process (HOP) 11

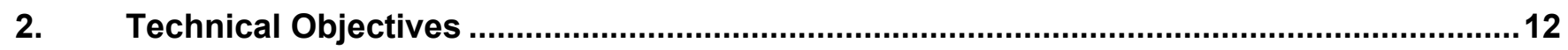

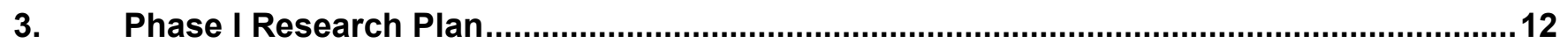

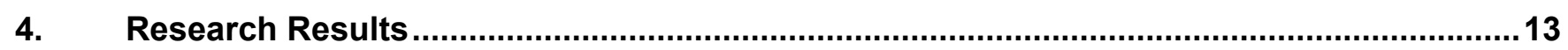

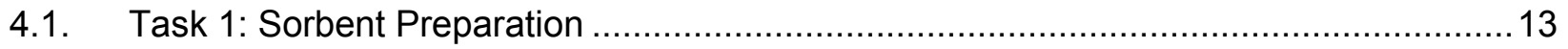

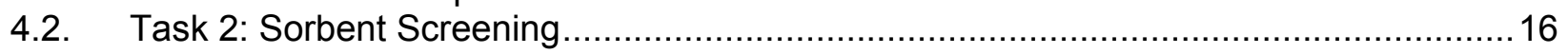

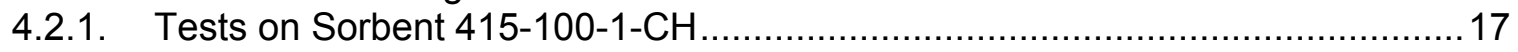

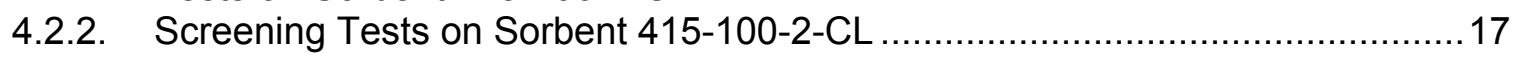

4.2.3. Screening Tests on Sorbent 415-100-3-CH (475-8) ................................ 18

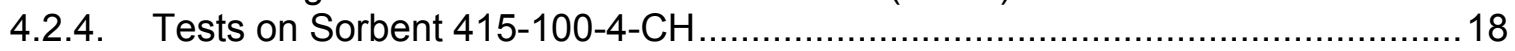

4.2.5. Sorbent properties before and after cycling ........................................... 20

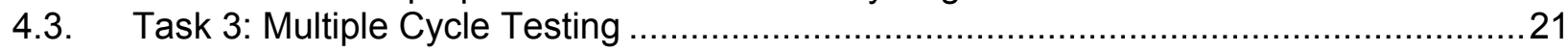

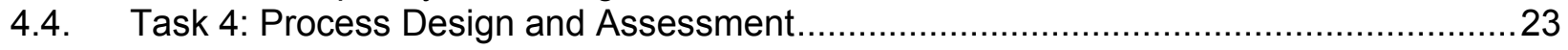

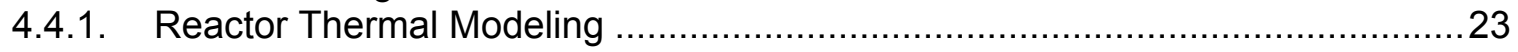

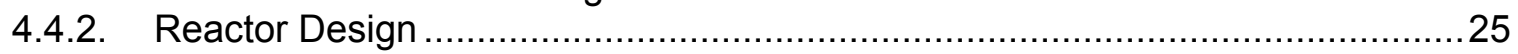

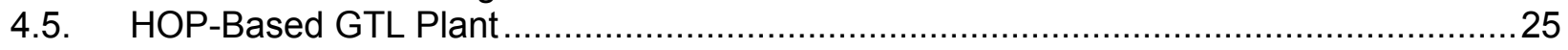

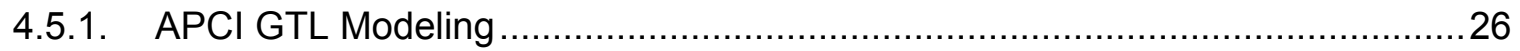

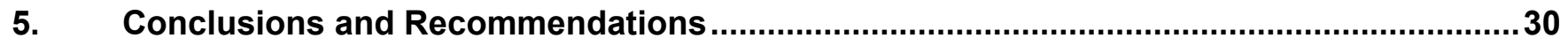

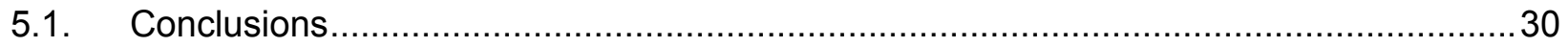

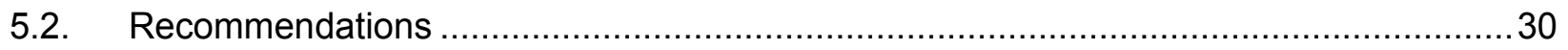




\section{List of Figures}

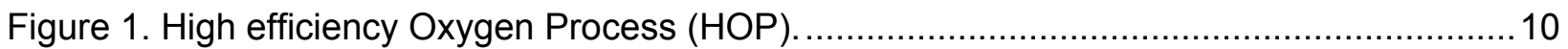

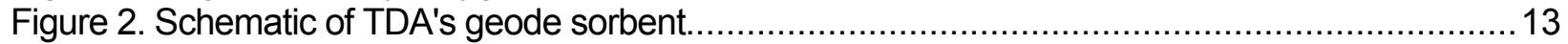

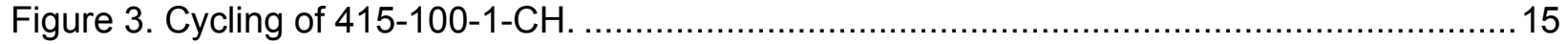

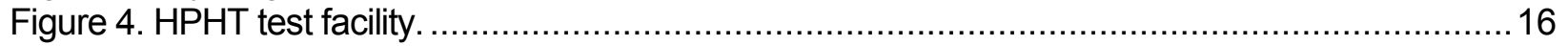

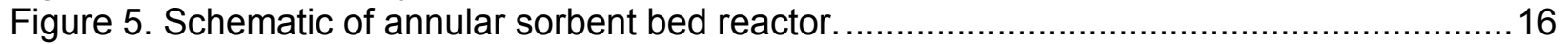

Figure 6. Cross-section of the reactor pressure vessel and annular reaction zone.................... 17

Figure 7. Comparison of analysis methods (sorbent 415-100-4-CH). .................................19

Figure 8. Equilibrium \& measured gas compositions $(415-100-4-\mathrm{CH})$.................................... 19

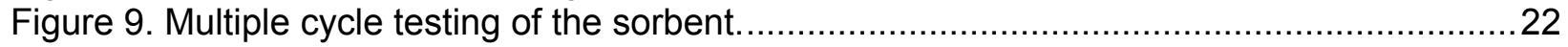

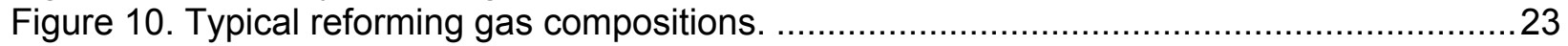

Figure 11. Reformed gas equilibrium for gas-to-liquids with high $\mathrm{CO}_{2}$ recycle.......................24

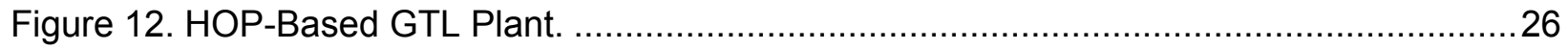

\section{List of Tables}

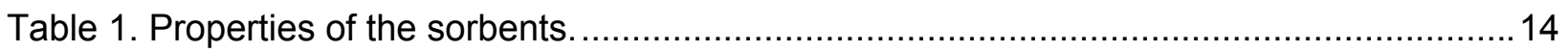

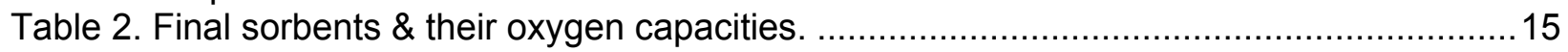

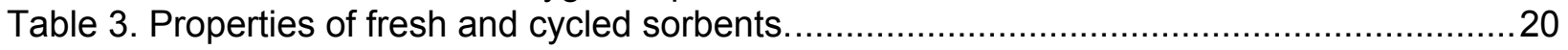

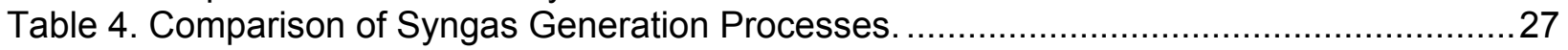

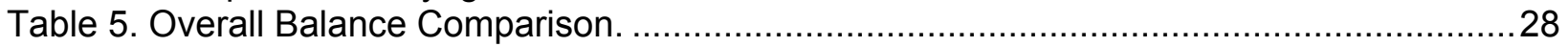

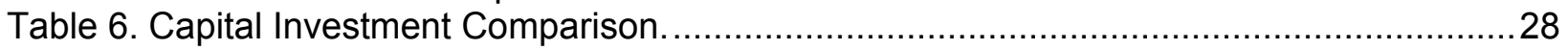

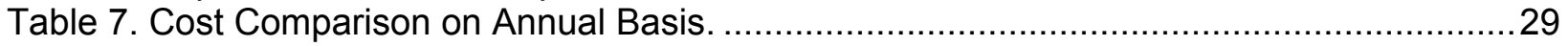

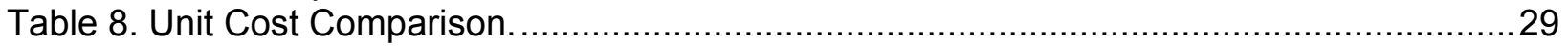




\section{Executive Summary}

Objective: This project investigated an efficient and low cost method of auto-thermally reforming natural gas to hydrogen and carbon monoxide. Reforming is the highest cost step in producing products such as methanol and Fisher Tropsch liquids (i.e., gas to liquids); and reducing the cost of reforming is the key to reducing the cost of these products. Steam reforming is expensive because of the high cost of the high nickel alloy reforming tubes (i.e., indirectly fired reforming tubes). Conventional auto-thermal or Partial Oxidation (POX) reforming minimizes the size and cost of the reformers and provides a near optimum mixture of $\mathrm{CO}$ and hydrogen. However POX requires pure oxygen, which consumes power and significantly increases the cost to reforming.

Methodology: Our high efficiency process extracts oxygen from low-pressure air with novel oxygen sorbent and transfers the oxygen to a nickel-catalyzed reformer. The syngas is generated at process pressure (typically 20 to 40 bar) without nitrogen dilution and has a $1 \mathrm{CO}$ to $2 \mathrm{H}_{2}$ ratio that is near optimum for the subsequent production of Fisher-Tropsch liquid to liquids and other chemicals (i.e., Gas to Liquids, GTL). Our high process efficiency comes from the way we transfer the oxygen into the reformer. All of the components of the process, except for the oxygen sorbent, are commonly used in commercial practice.

Benefits: A process based on a long-lived, regenerable, oxygen transfer sorbent could substantially reduce the cost of natural gas reforming to syngas. Lower cost syngas $\left(\mathrm{CO}+2 \mathrm{H}_{2}\right)$ that is the feedstock for GTL would reduce the cost of GTL and for other commercial applications (e.g., methanol, other organic chemicals). The vast gas resources of Alaska's North Slope (ANS) offer more than 22 Tcf of gas and GTL production in this application alone, and could account for as much as 300,000 to 700,000 bpd for 20 to $30+$ years.

Results: We developed a new sorbent, which is an essential part of the High Efficiency Oxygen Process (HOP). We tested the sorbent and observed that it has both a good oxygen capacity and operates as a highly effective reforming catalyst. We conducted a long duration tests of the sorbent (1,500 hours of continuous operation in the HOP cycle). Although the sorbent lost some oxygen capacity with cycling, the sorbent oxygen capacity stabilized after 1,000 hours and remained constant to the end of the test, 1,500 hour. The activity of the catalyst to reform methane to a hydrogen and carbon monoxide mixture was unchanged through the oxidation/reduction cycling. Our cost and performance analyses indicated a significant reduction in the cost of GTL production when using the HOP process integrated into a GTL plant.

\section{Participating Organizations}

TDA Research, Inc. (TDA)

Wheat Ridge, CO 80033
Air Products and Chemicals, Inc. (APCI)

Allentown, PA 


\section{Introduction}

Gas-to-Liquids (GTL) expands the options for the transport and marketability of the vast gas resources of Alaska's North Slope (ANS) and other remote gas resources. GTL using FischerTropsch (FT) technology is an obvious technology for getting the energy content of ANS gas to market, but current state-of-the-art FT technology is expensive due to the high cost-ofmanufacturing the syngas that is the feedstock for the GTL process. Syngas is the feedstock for the production of many major chemicals including $\mathrm{H}_{2}, \mathrm{CO}$, methanol and Fischer-Tropsch liquids. In the production of syngas based chemicals and fuels from Natural Gas (NG)( $94 \%$ $\mathrm{CH}_{4}$ ) the highly endothermic reforming reactions require heat; that heat can be provided by partially oxidizing the methane with oxygen. Partial oxidation produces the syngas with a ratio of $1: 1.8$ or less $\mathrm{CO}$ to $\mathrm{H}_{2}$, the ideal ratio for the production of chemicals.

The partial oxidation reaction (see Equation 1) is slightly exothermic and very favorable. However, even though oxygen is one of the lowest cost industrial chemicals (roughly $\$ 40 /$ ton from large scale cryogenic

Equation 1. Methane partial oxidation.

$\mathrm{CH}_{4}+1 / 2 \mathrm{O}_{2} \rightarrow \mathrm{CO}+2 \mathrm{H}_{2} @ 900^{\circ} \mathrm{C}$

$\Delta \mathrm{H}-5.34 \mathrm{kcal}, \Delta \mathrm{G}-60.6 \mathrm{kcal}$

air separation plants), it is still far too expensive to be used in the production of chemicals. For example, for Fischer-Tropsch processes that create liquid hydrocarbons from syngas produced by partial oxidation, oxygen at $\$ 40 /$ ton contributes $\$ 8.8 / \mathrm{bbl}$ to the cost of the hydrocarbons. The impact is similar for other chemical products. Clearly, less expensive ways of providing $\mathrm{O}_{2}$ to the process are essential.

Air Products and Chemicals, Inc. (APCI) is a major producer of syngas and supplier of oxygen. $\mathrm{APCl}$ recognized the above problem and identified a process and apparatus for producing syngas in a packed bed system. Natural gas is desulfurized and then pre-reformed to a mixture containing only $\mathrm{CH}_{4}, \mathrm{CO}_{2}, \mathrm{CO}$, steam and inert gases (e.g., $\mathrm{N}_{2}, \mathrm{He}$ ). The pre-reformate is then auto-thermally reformed in a system containing packed beds of oxygen sorbent and reforming catalyst.

In this project TDA developed the sorbent needed for the Air Product and Chemicals, Inc. (APCI) process, conduct experiments to show its ability to perform with multiple cycles, and conduct an economic assessment to evaluate the potential of this process with the participation of $\mathrm{APCl}$. APCl is very interested in this process and co-funded both its own work and part of the economic assessment performed by TDA.

\subsection{Gas to Liquids (GTL)}

Not all natural resources exist in close proximity to markets or pipelines. As operators scour the globe looking for new discoveries, increasingly large volumes of oil and gas are being found in remote areas, far offshore in the deep waters of the Gulf of Mexico or under the northern shore of Alaska. Oil, with its dense liquid state and relatively high value, can often be transported by ship or pipeline and still earn a profit. Gas, on the other hand is often left in the ground - its value wasted. Furthermore, gas that is incidentally produced along with oil is often burned at the well site, providing additional environmental and climate change concerns.

Natural gas-to-liquids (GTL) could have a significant impact on the liquid fuels market by increasing the use of natural gas to meet liquid fuel shortages. The liquids produced by GTL are generally considered to be ultra-clean transportation fuels that will mitigate the environmental 
impact of petroleum-based fuels. In addition, GTL fuels mitigates economic and energy security issues associated with maintaining a liquid fuels infrastructure in the U.S.

The reforming of hydrocarbons such as natural gas and naphtha to syngas $\left(\mathrm{H}_{2}\right.$ and $\left.\mathrm{CO}\right)$ is the first step in the production of a wide variety of products such as hydrogen, ammonia, methanol and Fisher Tropsch liquids. Most ( $80 \%)$ of the synthesis gas is produced by steam reforming with the remainder produced by partial oxidation (auto-thermal) reforming. Both processes are very expensive; steam reforming because of its high capital cost and auto-thermal reforming because of the high cost of the oxygen. The reforming process is by far the most expensive step in the production of methanol, hydrogen, ammonia and hydrocarbons from natural gas.

In the highly endothermic steam reforming process the feedstock (most often natural gas) is reacted with a large excess of steam over a nickel on alumina catalyst at high temperature in tubes enclosed in a fired heater: $\mathrm{CH}_{4}+\mathrm{H}_{2} \mathrm{O} \rightarrow \mathrm{CO}+3 \mathrm{H}_{2}$. There are several reasons that steam reforming (the dominant process) is very expensive:

1) Very expensive, super alloy (e.g., HP50 micro-alloy, a cast high nickel alloy) tubes are needed to contain the high temperature high pressure $\left(870^{\circ} \mathrm{C}, 20 \mathrm{~atm}\right)$ reforming stream;

2) The HP50 micro-alloy heat exchanger is very large due the large quantity of heat required by the reaction, the low coefficient of heat transfer on both the flame and reforming gas sides of the tube, the high thermal resistance for heat transfer through the nickel/alumina catalyst, and the low temperature difference between the tube wall reforming gas (necessary to prevent burning out the tubes).

3) The tube walls must be very thick to hold the pressure at the high operating temperature.

4) The $\mathrm{H}_{2} / \mathrm{CO}$ ratio produced by steam reforming is higher than is needed for the production of methanol and Fischer-Tropsch liquids, resulting in oversized reformers.

5) Large quantities of excess steam are required to prevent coking in the reformer and the downstream equipment.

It is well known that most of these problems can be eliminated or reduced by using partial oxidation or auto-thermal reforming. In this process, a limited amount of pure oxygen is supplied to the reformer. The oxygen oxidizes the carbon to $\mathrm{CO}$, producing heat and hydrogen in the process (Schneider and Joshi 1997, Kirk-Othmer 1996):

$$
\mathrm{CH}_{4}+1 / 2 \mathrm{O}_{2} \rightarrow \mathrm{CO}+2 \mathrm{H}_{2}
$$

Since the heat is internally generated by the production of the $\mathrm{CO}$, the large, expensive super alloy tubes can be replaced with an inexpensive internally insulated carbon steel pressure shell.; this greatly reduces capital cost. The process generates two $\mathrm{H}_{2}$ per mole of methane instead of the $3 \mathrm{H}_{2}$ generated by steam reforming, an advantage for methanol synthesis and the FischerTropsch process. Unfortunately, in spite of the many advantages of auto-thermal reforming, the cost of the oxygen more than offsets the capital and other operating cost savings. In spite of the high cost of oxygen, auto thermal reforming is the preferred method of producing syngas. What we need is an inexpensive method of providing oxygen to a partial oxidation reformer.

The high cost of oxygen is due partially to the large capital investment required to build a cryogenic air separation plant (the most cost effective method of large scale oxygen separation) and the large amount of energy (input as electricity to drive the compressors) needed to separate oxygen from air. This large energy consumption is inherent in any process, which separates air into pure oxygen and nitrogen. However, the reforming process does not require 
that the oxygen be supplied as pure, gaseous oxygen. it merely requires that the oxygen be supplied without bringing along any nitrogen (an inert which can seriously harm the economics of the downstream processes). There is plenty of driving force inherent in the methane/synthesis gas stream to remove oxygen from air and pull it into the reformer. Oxygen partial pressures are on the order of $10^{-23} \mathrm{~atm}$ in the syngas, compared to $0.2 \mathrm{~atm}$ in air (or more in a pressurized air stream). What we need is a method of harnessing this driving force to pull the oxygen into the reformer without bringing along any nitrogen.

\subsection{How the Proposed Work Will Result in Improvements Over Existing Technologies}

At the large scale, cryogenic separation is currently the lowest cost oxygen separation process (Ion Transfer Membranes, ITM are being developed and are anticipated to reduce the cost of oxygen by $1 / 3$; i.e., from the $\sim \$ 40$ /ton of oxygen by cryogenic separation to $\sim \$ 30 /$ ton with ITM). Although the percentages vary as a function of local electrical costs, oxygen purity and scale, roughly a quarter to a third of the cost of the oxygen is due to the electricity that drives the air separation, and the remainder is due to the high capital cost of the cryogenic equipment. The high capital cost is a result of the close approach temperatures used in the cryogenic heat exchangers, which make the exchangers large and expensive. (Very close approach temperatures are needed if cryogenic processes are to be energy efficient). Clearly, the cost of oxygen could be reduced if we could eliminate need for electrical energy to drive the separation. Additionally, if we didn't need to work so hard to minimize energy consumption, capital costs could be reduced as well.

While the separation of any mixture (such as air) requires an energy input, the work doesn't need to be supplied as electricity or shaft work. In fact, in supplying oxygen to a partial oxidation process, the energy needed to separate oxygen from the air could be provided by the reducing power of the natural gas. Since our objective is to supply oxygen to the fuel gas, not produce pure oxygen, and the equilibrium partial pressure of oxygen in any of these gases is on the order of $10^{-20} \mathrm{~atm}$, they can extract oxygen from air with essentially no additional energy consumption.

Air Products and Chemicals, Inc. (APCl) recognized the above facts and identified a fixed bed process, which could separate oxygen from low-pressure air and deliver it at high pressure for partial oxidation of natural gas. Air at $\sim 10$ psig flows over a packed bed of oxygen sorbent and oxidizes; the heat release of this highly exothermic reaction is contained within the bed entirely by its sensible heat capacity. When essentially all of the sorbent is oxidized, the bed is swept and pressurized with steam and then switched to a feed of pre-reformate (a mix of $\mathrm{CH}_{4}, \mathrm{H}_{2}, \mathrm{CO}, \mathrm{H}_{2} \mathrm{O}$ and $\mathrm{CO}_{2}$ ). The reducing power of the fuel gases in this feed reduces the oxidized sorbent, which catalyzes the further conversion of the $\mathrm{CH}_{4}$ to syngas.

Even in auto thermal reforming, excess steam is (HOP).

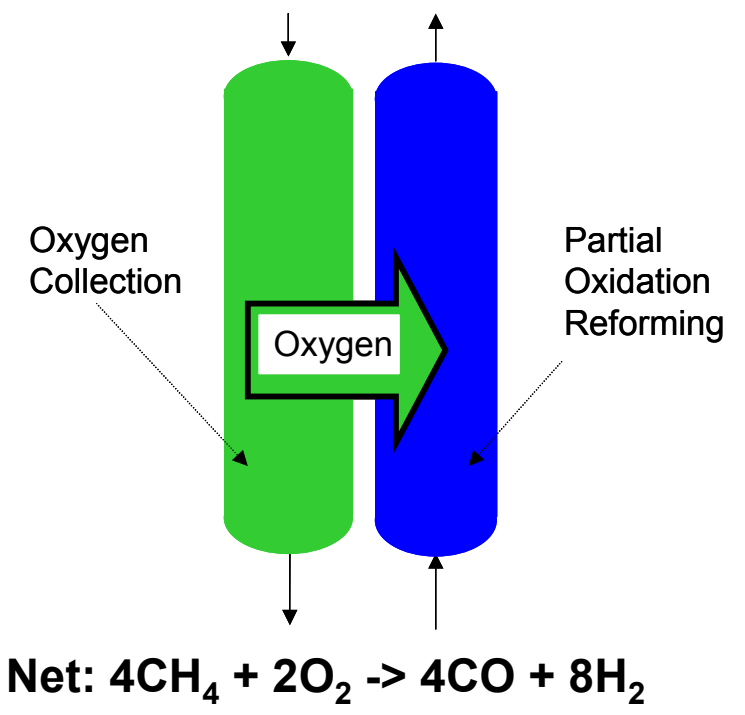

Figure 1. High efficiency Oxygen Process necessary to inhibit coking in the reactors. Although nickel is known to catalyze coking and 
reforming, previous work has shown that steam in the range of $\mathrm{H}_{2} \mathrm{O} / \mathrm{C}>1.5$ will prevent coking in typical stream reforming systems with nickel catalysts. In addition, pre-reforming a steam/natural gas mix prior to the main reactors converts all hydrocarbons heavier than methane into extinction, and is a widely used method of reducing coking in high temperature reactors. In addition, our system periodically flows air at high temperature over the sorbent (i.e., 800 to $1050^{\circ} \mathrm{C}$ ), which burns off any coke that happens to form. The latter feature could allow the use of an even lower steam to carbon ratio than conventional systems to produce a system with significantly improved efficiency (due to the reduced heat required to generate steam).

\subsection{Potential for a Scientific or Engineering Breakthrough}

Fortunately, almost all of the HOP components, except the regenerable oxygen sorbent, are commonly used in industry. Fixed bed absorption and adsorption units (e.g., pressure swing adsorption, PSA) are frequently used in chemical processing and the associated valving and control functions are well understood and practiced. POX reforming (also called auto-thermal reforming) is commercially practiced by $\mathrm{APCl}$ and others to produce a syngas feedstock because POX provides the near optimum mixture of $\mathrm{CO}$ and hydrogen needed for producing.

While the separation of any mixture (such as air) requires an energy input, the work doesn't need to be supplied as electricity. In fact, if we are supplying oxygen to a partial oxidation process, the energy needed to separate oxygen from the air could be provided by the reducing power of the natural gas. Since our objective is to supply oxygen to the fuel gas, not produce pure oxygen, and the equilibrium partial pressure of oxygen in any of these gases is on the order of $10^{-20} \mathrm{~atm}$, they can extract oxygen from air with essentially no energy consumption.

TDA's sorbents have another inherent advantage: they are substantially less expensive. Our previous work in geodes has shown that we can produce sorbents with surface areas $>@$ $1 \mathrm{~m}^{2} / \mathrm{g}$. Saint Gobain NorPro (formerly Norton Chemical Process Products Corp.), our sorbent supplier, has estimated the cost for production quantities at $\sim \$ 5 / \mathrm{lb}(\$ 10.1 / \mathrm{kg}=\$ 0.0101 / \mathrm{g})$. There the reactive area of the sorbent cost $\$ 0.0101 / \mathrm{g} / 1 \mathrm{~m}^{2} / \mathrm{g}=\$ 0.0101 / \mathrm{m}^{2}$ or $\$ 0.00102 / \mathrm{ft}^{2}$. This low cost for reactive surface area gives our HOP the potential for very low capital cost for the separation of oxygen from air. The low capital cost combined with the high efficiency of using the inherent chemical potential of the fuel which is being reformed gives the HOP the potential to transfer oxygen and reform natural gas to syngas at very low costs.

\subsection{The Scientific and Technical Basis and Merit of the High [efficiency] Oxygen Process (HOP)}

We call this fixed bed oxygen transfer system a "High [efficiency] Oxygen Process" (HOP). HOP will separate oxygen from air with both high efficiency and low cost. The process is based on a regenerable, long-life, oxygen sorbent that transfers oxygen from the air into a reformer where it supplies oxygen for the partial oxidation of NG. The process uses the reducing power of the fuel to reduce the oxides back to a lower valence state and then to use the conventional reforming catalyst (e.g., Ni) to reform the natural gas. Therefore, HOP transfers oxygen from the air to the reformer with essentially zero incremental energy consumption.

At the end of the oxidation, a mixture of methane and steam enter at the Reactor. The methane steam mixture first reduces the reduces the oxygen sorbent and then is reformed by the catalyst producing a gas stream with the same composition as Equation 1. 


\section{Technical Objectives}

A sorbent is needed which can absorb $\mathrm{O}_{2}$ at the conditions of interest and reform natural gas to the desired $\mathrm{CO}+2 \mathrm{H}_{2}$ mixture. Due to the substantial reduction in the cost of oxygen that the process offers, the partial oxidation system can be very efficient, but we need to include the cost of the equipment to determine if this technology will have good commercial application. Therefore, the objectives of the work were 1) to develop sorbents, 2) to test their performance under simulated reformer gas and regeneration gas conditions, and 3 ) to assess the economic potential of the process for industrial hydrogen/CO (HYCO) applications.

\section{Phase I Research Plan}

TDA divided the work into five tasks. In Task 1 we selected starting materials and screened them to quickly eliminate those with unacceptable physical properties. In Task 2, we exposed several candidate sorbents to simulated partially reformed natural gas and regenerated them with air. In Task 3 , we selected sorbents and tested them for multiple cycle testing in our High Temperature High Pressure (HTHP) test facility. In Task 4, we conducted a preliminary process design and an economic analysis of the sorbent/catalyst system. The results are reported in Task 5.

Following the final review, DOE identified the need for additional cycling of one sorbent. Since previous work on catalysts has shown a loss of activity up until 1,000 to 1,200 hours, DOE funded an extension to Task 3 to test one sorbent for 1,500 hours to evaluate the effect of time and cycling on both oxygen capacity and catalytic activity. 


\section{Research Results}

TDA conducted research to develop strong, sorbents with high oxygen loading. We screened the sorbents conducted multiple cycle testing and prepared an economic analysis of the HOP.

TDA has extensive experience in developing long life, regenerable, chemical sorbents. We have developed sorbents for fixed bed, moving bed, fluidized bed, and transport reactors, and use a variety of active sorbents $\left(\mathrm{CaO}, \mathrm{CuO}, \mathrm{Fe}_{2} \mathrm{O}_{3}, \mathrm{MgO}, \mathrm{Na}_{2} \mathrm{CO}_{3}, \mathrm{SnO}_{2}, \mathrm{ZnO}\right.$ ) to regenerably absorb and desorb reactive gases $\left(\mathrm{CO}_{2}\right.$, $\mathrm{HCl}, \mathrm{H}_{2} \mathrm{~S}, \mathrm{NO}_{x}, \mathrm{SO}_{2}$ ).

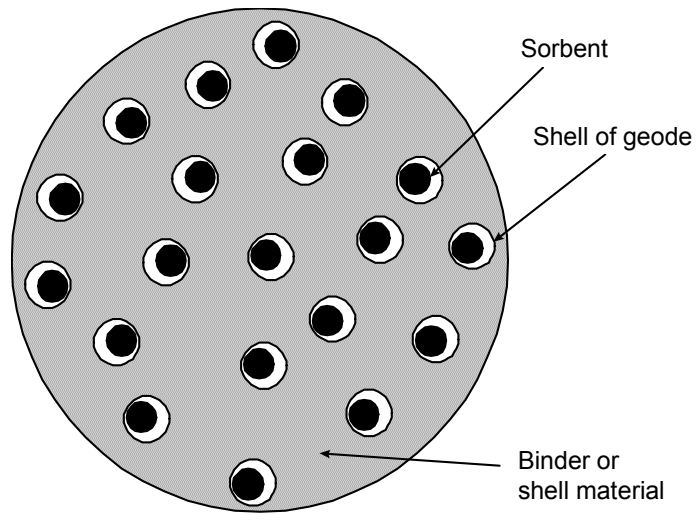

Figure 2. Schematic of TDA's geode sorbent.

TDA's regenerable chemical sorbents have the type of characteristics needed in this process. The trick is to make a regenerable sorbent pellet which: 1) contains a large amount of active chemical (e.g., $\mathrm{Ni} \leftrightarrow \mathrm{NiO}$ )(i.e., high surface area), yet still has the strength to withstand the structural loads, 2) will hold together during the large expansion and contraction which accompanies the absorption and removal of the oxygen, and 3) which is chemically stable. We achieve these goals using a structure that we call a "geode" (Figure 2). Like the geode that you buy at a gift shop, our geode has a hollow shell. However, unlike the gem shop geode that has a single hole in the middle, our geode sorbent contains hundreds or thousands of holes in a structure that looks like a conventional catalyst pellet on the outside. The sorbent is loosely contained in, but does not fill the hole(s) in the center. Thus, the sorbent can expand and contract indefinitely without destroying the pellet structure. In addition, since the body of the pellet contains the sorbent but does not need to have sorbent properties, we can make the shell of the pellet out of strong but inert and highly porous materials such as alumina, silica, or titania (materials that are commonly used as catalyst and sorbent supports in applications where porosity, strength, attrition resistance and chemical inertness are essential).

\subsection{Task 1: Sorbent Preparation}

TDA prepares several sorbent with different active ingredients (i.e., chemically active oxygen sorbent), inert ingredients, and firing conditions. We then screened the sorbents based on their strength, oxygen loading (as measured in a Thermo-Gravimetric analyzer (TGA)].

Table 1 presents the sorbent formulations and the properties of each when fired at six different temperatures (Temperature B was not performed). Surface area was measure by BET. Crush strength was measured based on the average force per unit length of the cylindrical pellets required to crush the pellets. Porosity was measured as the "wetablity" or quantity of water that the sorbents will retain (sum of micro and macro porosity). Porosity BET is a measure of the micro porosity of the sorbent. 
Table 1. Properties of the sorbents.

\begin{tabular}{|c|c|c|c|c|c|}
\hline $\begin{array}{l}\text { Sample } \\
\text { ID number }\end{array}$ & $\begin{array}{c}\text { Firing } \\
\text { temperature }\end{array}$ & $\begin{array}{c}\text { Surface } \\
\text { area }\left(\mathrm{m}^{2} / g\right)\end{array}$ & $\begin{array}{l}\text { Crush strength } \\
\text { (Ib/mm) }\end{array}$ & $\begin{array}{l}\text { Porosity } \\
\text { (cc/g) }\end{array}$ & $\begin{array}{c}\text { Porosity } \\
\text { (BET) (cc/g) }\end{array}$ \\
\hline & $\mathrm{A}$ & 4.75 & 1.92 & 0.43 & 0.0218 \\
\hline \multirow[t]{4}{*}{ 415-100-1 } & $\mathrm{C}$ & 2.61 & 2.60 & 0.40 & 0.0072 \\
\hline & $\mathrm{D}$ & 1.69 & 3.64 & 0.33 & 0.0008 \\
\hline & $E$ & 0.41 & 6.02 & 0.26 & 0.0001 \\
\hline & $\mathrm{F}$ & 0.01 & 9.69 & 0.15 & 0.0000 \\
\hline \multirow[t]{5}{*}{$415-100-2$} & $A$ & 0.57 & 7.26 & 0.24 & 0.0003 \\
\hline & $\mathrm{C}$ & $\mathrm{n} / \mathrm{a}$ & 7.76 & 0.17 & $\mathrm{n} / \mathrm{a}$ \\
\hline & $\mathrm{D}$ & 1.98 & 8.41 & 0.18 & 0.0006 \\
\hline & $E$ & ${ }^{*}$ & 10.64 & 0.14 & $\mathrm{n} / \mathrm{a}$ \\
\hline & $\mathrm{F}$ & * & 12.28 & 0.11 & $\mathrm{n} / \mathrm{a}$ \\
\hline \multirow[t]{5}{*}{$415-100-3$} & $\mathrm{~A}$ & 2.98 & 2.84 & 0.36 & 0.0013 \\
\hline & $\mathrm{C}$ & 1.74 & 3.42 & 0.35 & 0.0041 \\
\hline & $\mathrm{D}$ & 0.92 & 5.21 & 0.26 & 0.0004 \\
\hline & $\mathrm{E}$ & 0.03 & 10.23 & 0.16 & 0.0000 \\
\hline & $\mathrm{F}$ & 0.01 & 15.66 & 0.09 & 0.0000 \\
\hline \multirow[t]{5}{*}{ 415-100-4 } & $\mathrm{A}$ & 2.79 & 4.82 & 0.23 & 0.0012 \\
\hline & $\mathrm{C}$ & 2.28 & 4.70 & 0.23 & 0.0076 \\
\hline & $\mathrm{D}$ & 2.15 & 5.12 & 0.23 & 0.0010 \\
\hline & $E$ & 1.55 & 5.74 & 0.19 & 0.0028 \\
\hline & $F$ & 0.94 & 7.24 & 0.15 & 0.0019 \\
\hline
\end{tabular}

${ }^{*}$ Too low to be meaningful

The expected operating temperatures are in the range of $650^{\circ} \mathrm{C}$ to $1,050^{\circ} \mathrm{C}$. All of the temperatures (i.e., A through $\mathrm{F}$ in Table 1) are more than $100^{\circ} \mathrm{C}$ higher than the highest operating temperature.

Sample 415-100-1-C was identified as one that has good mechanical strength, high porosity and moderately high surface area (i.e., potential for good reaction rates). The micro-porosity was also moderately high. Using a TGA, we conducted several test cycles isothermally on sample $415-100-1-\mathrm{C}$. The sorbent was reduced with a gas stream of $2 \% \mathrm{H}_{2}, 10 \% \mathrm{CO}_{2}$, and the balance of helium, and then oxidized with air. The reducing gas flowed for 30 minutes and the air for 20 minutes (see Figure 3). Initially the sorbent's oxygen capacity was relatively low, but after a few cycles it stabilized at 3.7\%. Note: there are small spikes in the TGA weight trace that are associated with stopping one gas flow and then starting the other. 


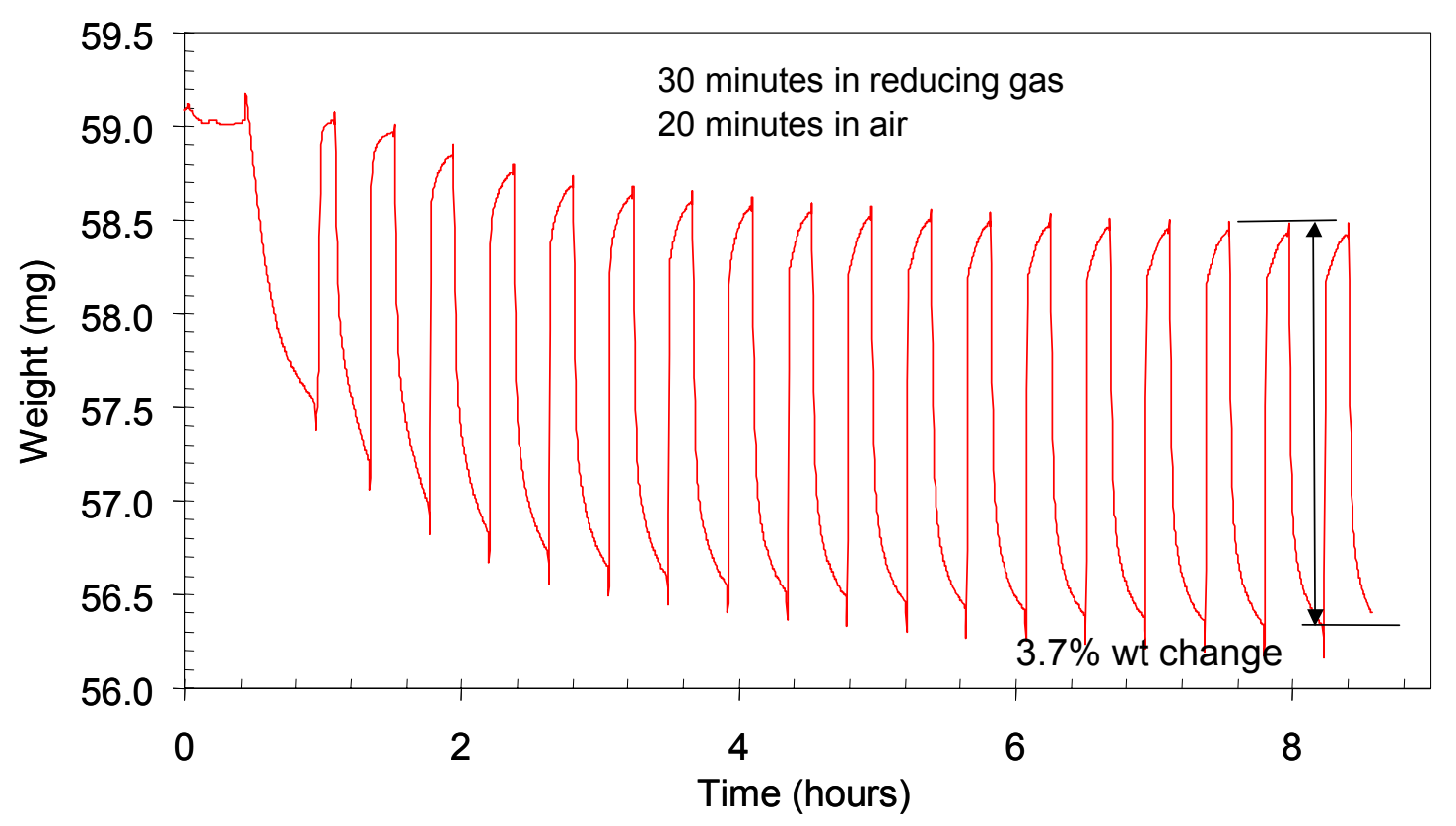

Figure 3. Cycling of 415-100-1-CH.

This sorbent achieved an initial oxygen loading of 3.7. However, with continuing cycling, the sorbent capacity decreases to $3.34 \%$, where it stabilized.

Table 2 shows the oxygen loadings of the four most promising sorbent formulations, with information on each pertaining to the quantity of the chemically active compound in the sorbent [called low $(\mathrm{L})$ and high $(\mathrm{H})$ ].

Since high oxygen capacities are desirable, the " $H$ " version of $-1,-3$, and -4 sorbent were selected for additional testing. Table 2. Final sorbents \& their oxygen capacities.

\begin{tabular}{lll}
\hline Sample ID & $\begin{array}{l}\text { Oxygen } \\
\text { capacity (\%) }\end{array}$ & $\begin{array}{l}\text { Number of } \\
\text { TGA cycles }\end{array}$ \\
\hline $415-100-1-\mathrm{CL}$ & 1.21 & $25 ;$ stable \\
$415-100-1-\mathrm{CH}$ & 3.34 & 27 ; stable \\
\hline $415-100-2-\mathrm{CL}$ & 4.04 & $24 ;$ stable \\
$415-100-2-\mathrm{CH}$ & 4.96 & $24 ;$ stable \\
\hline $415-100-3-\mathrm{CH}$ & 1.54 & $23 ;$ stable \\
\hline $415-100-4-\mathrm{CL}$ & 3.30 & $25 ;$ stable \\
$415-100-4-\mathrm{CH}$ & 5.77 & 21, rising \\
\hline
\end{tabular}

The "L" version was selected

for the -2 sorbent, since there was little difference between the two versions and both were high. 


\subsection{Task 2: Sorbent Screening}

We prepared a larger batch of the " $\mathrm{H}$ " version of all four sorbents and test them in our High Temperature High Pressure (HTHP) test facility. Figure 4 is a photograph of TDA's High Temperature High Pressure (HTHP) test facility. The apparatus incorporates several mass flow controllers used to mix gases to simulate a broad range of gas streams. The flows of $\mathrm{N}_{2}, \mathrm{CH}_{4}, \mathrm{CO}$, $\mathrm{CO}_{2}$, steam, and air are independently controlled. Steam is added to the system by using a high-pressure liquid chromatography pump to inject water into a boiler tube located below the sorbent beds. A tube furnace capable of $2,012^{\circ} \mathrm{F}\left(1,100^{\circ} \mathrm{C}\right)$ operation is used to heat the fixed bed sorbent reactors. Each of the two reactors is a 2.5-inch (ID) tube with a six-inch isothermal zone. The current three-inch Inconel reactor is capable of operating up to $1,922^{\circ} \mathrm{F}\left(1050^{\circ} \mathrm{C}\right)$, with pressures up to $100 \mathrm{psig}$. We have an on-line computer control system to measure and control temperatures, flow rates, and gas compositions, which allows $24 \mathrm{~h}$ operation, and a number of safety devices. The computer monitors the operation of the experiment and shuts down all gas supplies, heaters, etc., if any parameter goes out of range. In addition, gas sensors can independently shut down the

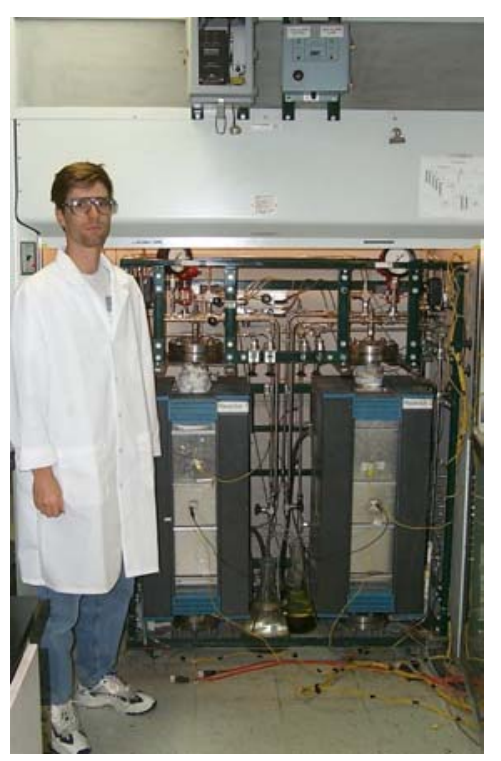

Figure 4. HPHT test facility. system if any gas concentration in the laboratory exceeds preset limits.

Figure 5 presents a schematic of the loading of the sorbent in the annular sorbent bed reactor. This configuration uses $1 / 16^{\text {th }}$ inch dia. pellets $(L / D \sim 1)$ in a 2.5 " ID with a 1.0 " annulus. All of the components are Inconel, due to the high temperatures required in these tests. This annular flow design was selected to allow heat to be transfer into the reactor during reforming and therefore we can measure the reformed products under steady state conditions and be able to screen the sorbents for the catalytic activity for reforming.

The reactor is externally heated by the tube furnace on the outside of the pressure wall of the annular sorbent bed reactor. Thermocouples are mounted in the thermocouple well in the center of the

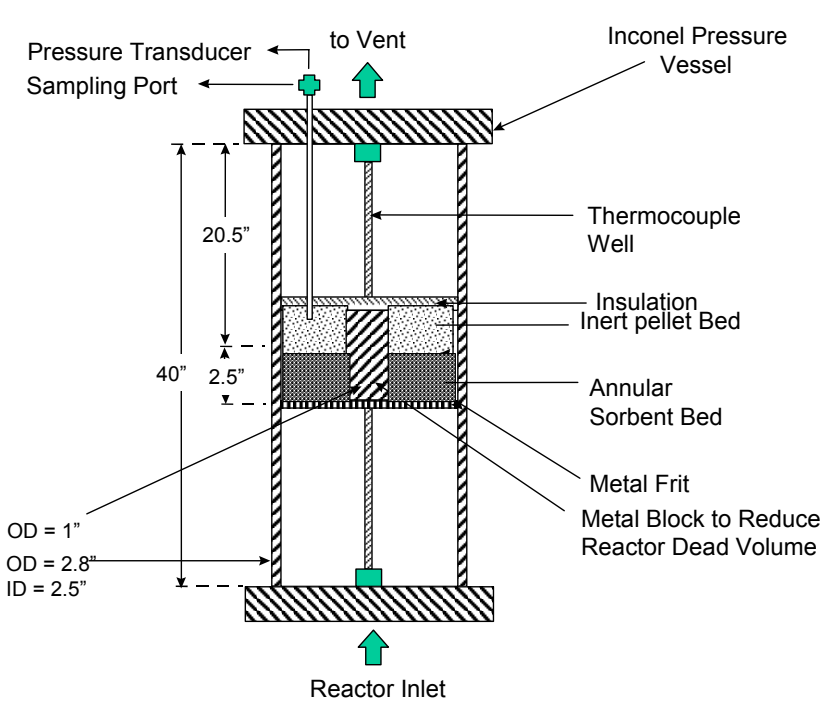

Figure 5. Schematic of annular sorbent bed reactor. reactor at three locations (near the bottom, center, and top of the sorbent bed) and on the outside of the pressure vessel at two locations (bottom and middle of the sorbent bed).

All of these tests were designed to measure the catalytic reforming activity of the sorbent. The measurements were made under steady state conditions with the heat required for reforming delivered by the electrically heated tube furnace. After each steady state measurement, the sorbent was oxidized and then reduced before moving to the next higher temperature for reforming. 
Figure 6 presents a schematic of the loading of the sorbent in the annular sorbent bed reactor. This configuration uses $1 / 16^{\text {th }}$ inch dia. pellets $(L / D \sim 1)$ in a 2.5 " ID with a 1.0 " annulus. All of the components are Inconel, due to the high temperatures required in these tests. This annular flow design was selected to allow heat to be transferred into the reactor during reforming so that we could 1) measure the reformed products under steady state conditions and 2) screen the nickel-based sorbents for the catalytic activity for reforming.

The reactor is externally heated by the tube furnace on the outside of the pressure wall of the annular sorbent bed reactor.

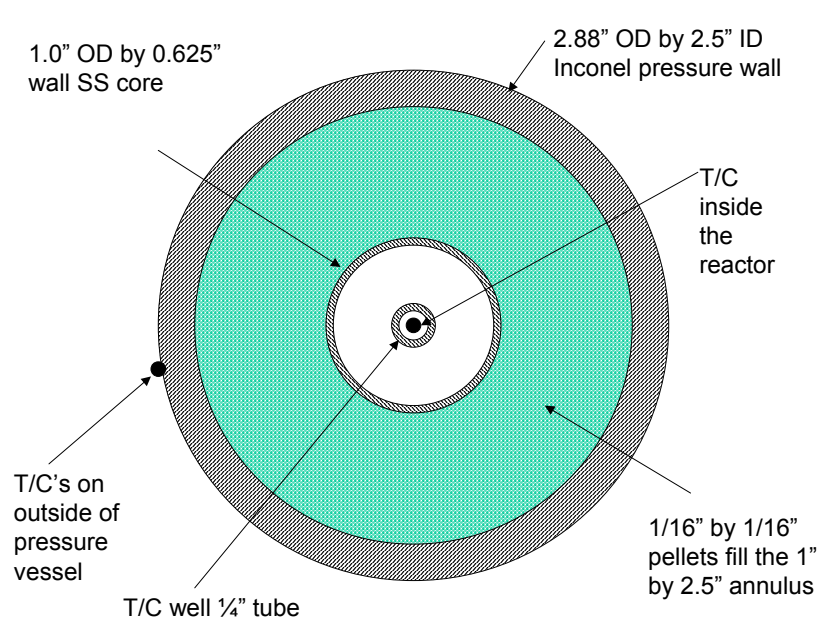

Figure 6. Cross-section of the reactor pressure vessel and annular reaction zone. Thermocouples are mounted in the thermocouple well in the center of the reactor at three locations (near the bottom, center, and top of the sorbent bed) and on the outside of the pressure vessel at two locations (bottom and middle of the sorbent bed).

Gas compositions are measured using continuous monitors for oxygen, methane, carbon monoxide and carbon dioxide. Water is condensed out of the gases stream and the data are reported on a dry gas basis. A gas chromatograph (GC) is used to measure hydrogen and argon concentrations. A metered flow of argon is injected downstream of the reactor to dilute the gases so that the maximum concentration of $\mathrm{CH}_{4}, \mathrm{CO}$, or $\mathrm{CO}_{2}$ does not exceed $25 \%$ (full scale on our continuous monitors). During oxidation, the maximum $\mathrm{O}_{2}$ concentration is $21 \%$. We do not dilute the outlet with argon.

\subsubsection{Tests on Sorbent $415-100-1-\mathrm{CH}$}

We tested the $415-100-1-\mathrm{CH}$ sorbent for 21 cycles with a mixture of $30 \%$ methane, $25 \%$ carbon dioxide, and $45 \%$ steam. The sorbent sample $415-100-1-\mathrm{CH}$ was first fully reduced and then the gas stream reformed at $11 \mathrm{~atm}(147 \mathrm{psig})$ and 2,000 $\mathrm{h}^{-1}$ space velocity. Four reforming tests were performed, and the sorbent/catalyst was re-oxidized at the end of each run. During the oxidation, we measured the outlet gas concentrations and flow rates

The 415-100-1-CH sorbent performed well under all operating conditions of the HOP. Oxidation removes $99 \%$ of the oxygen. Reforming converts the methane to $\mathrm{CO}$ and $\mathrm{H}_{2}$ without $\mathrm{CH}_{4}$ leakage, even when reforming lowers the sorbent temperature. This sorbent has the potential to meet our requirements for the HOP.

\subsubsection{Screening Tests on Sorbent 415-100-2-CL}

TDA tested sorbent sample 415-100-2-CL. The sorbent demonstrated a high activity level during reforming and a stable oxygen capacity through 20 cycles. However, there were losses of mass and the sorbent had turned to powder when we examined the reactor following the tests. These tests with the 415-100-2-CL were conducted to reach the maximum temperature expected in the HOP cycle. 
Previously the 415-100-2-CL had been tested in our TGA for multiple cycles but at slightly higher than the average temperature during the HOP cycle but not the maximum temperature. The TGA tests were conducted on whole pellets and the pellets did not powder during the cycling.

Clearly, the higher temperature caused the damage to the 415-100-2-CL sorbent and the tests demonstrated the importance of testing at the highest temperature of the HOP cycle. All of the tests on other sorbents were conducted so that the sorbents reached the highest temperature every cycle.

\subsubsection{Screening Tests on Sorbent 415-100-3-CH (475-8)}

We conducted 27 cycles on the $475-8$ sorbent (a remake of the $415-100-3-\mathrm{CH}$ sorbent) at a space velocity $\left(2,000 \mathrm{~h}^{-1}\right)$. At the end of the reforming, the measured hydrogen, carbon monoxide, carbon dioxide, and methane concentrations were very close to equilibrium values.

The 475-8 sorbent performed well under all operating conditions of the HOP. Oxidation removes $99 \%$ of the oxygen. Reforming converts the methane to $\mathrm{CO}$ and $\mathrm{H}_{2}$ without $\mathrm{CH}_{4}$ leakage, even when reforming lowers the sorbent temperature. This sorbent has the potential to meet our requirements for the HOP.

\subsubsection{Tests on Sorbent $415-100-4-\mathrm{CH}$}

Sorbent sample 415-100-4-CH had the best TGA results, good mechanical strength, high porosity, and moderately high surface area (i.e., potential for good reaction rates). We prepared a larger batch of this material and loaded it into our HTHP test facility. We loaded the reactor with the $415-100-4-\mathrm{CH}$ sorbent, which has a bulk density of $1.51 \mathrm{~g} / \mathrm{cc}$. All of the pellets were extrudates sized to $1 / 16 "$ dia. and $\sim 1 / 16$ " long.

TDA used two different methods in the tests to determine gas composition. One method adjusts the readings of the monitors based on the GC measurements of argon concentration in the dry gas stream. The other method adjusts monitor data based on a required carbon balance and calculates hydrogen concentration as $1-\mathrm{CO}-\mathrm{CO}_{2}-\mathrm{CH}_{4}$. Figure 7 presents a comparison of the two methods. The data from the two methods are in agreement, except for the hydrogen. After conducting the tests we re-calibrated the GC for hydrogen and found that it was reading about $10 \%$ high (due to an un-intended change in the carrier gas flow). The carbon balance method is estimated to be the more accurate, and also provides continuous data for all of the gases of interest. 


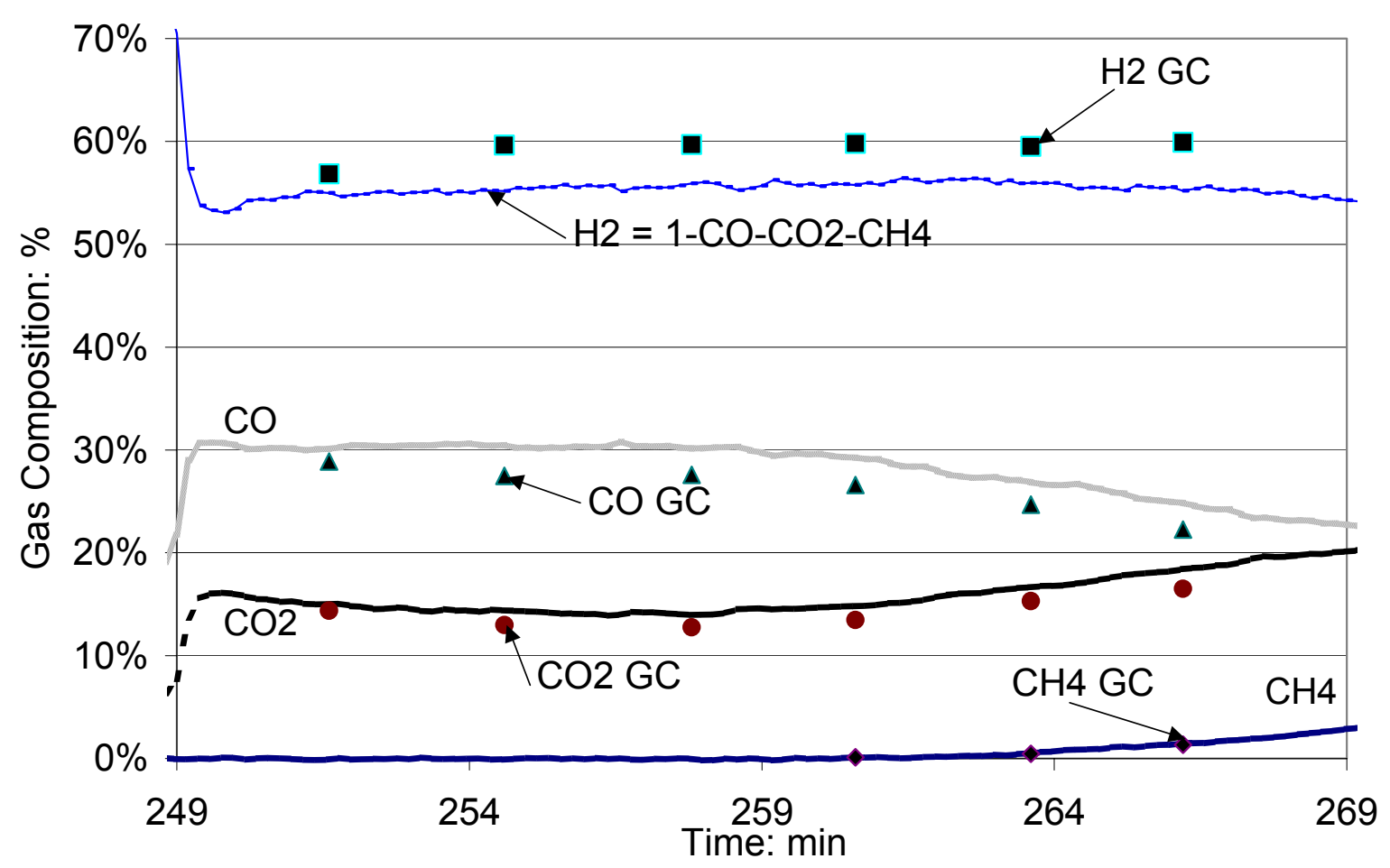

Figure 7. Comparison of analysis methods (sorbent 415-100-4-CH).

Near isothermal reforming tests at steady state conditions were performed using the heat transferred through the pressure wall from a tube furnace. These tests showed that we were operating at near equilibrium conditions. Figure 8 presents a comparison of the calculated equilibrium based on the inlet gas flows (large circles) with the measured gas compositions

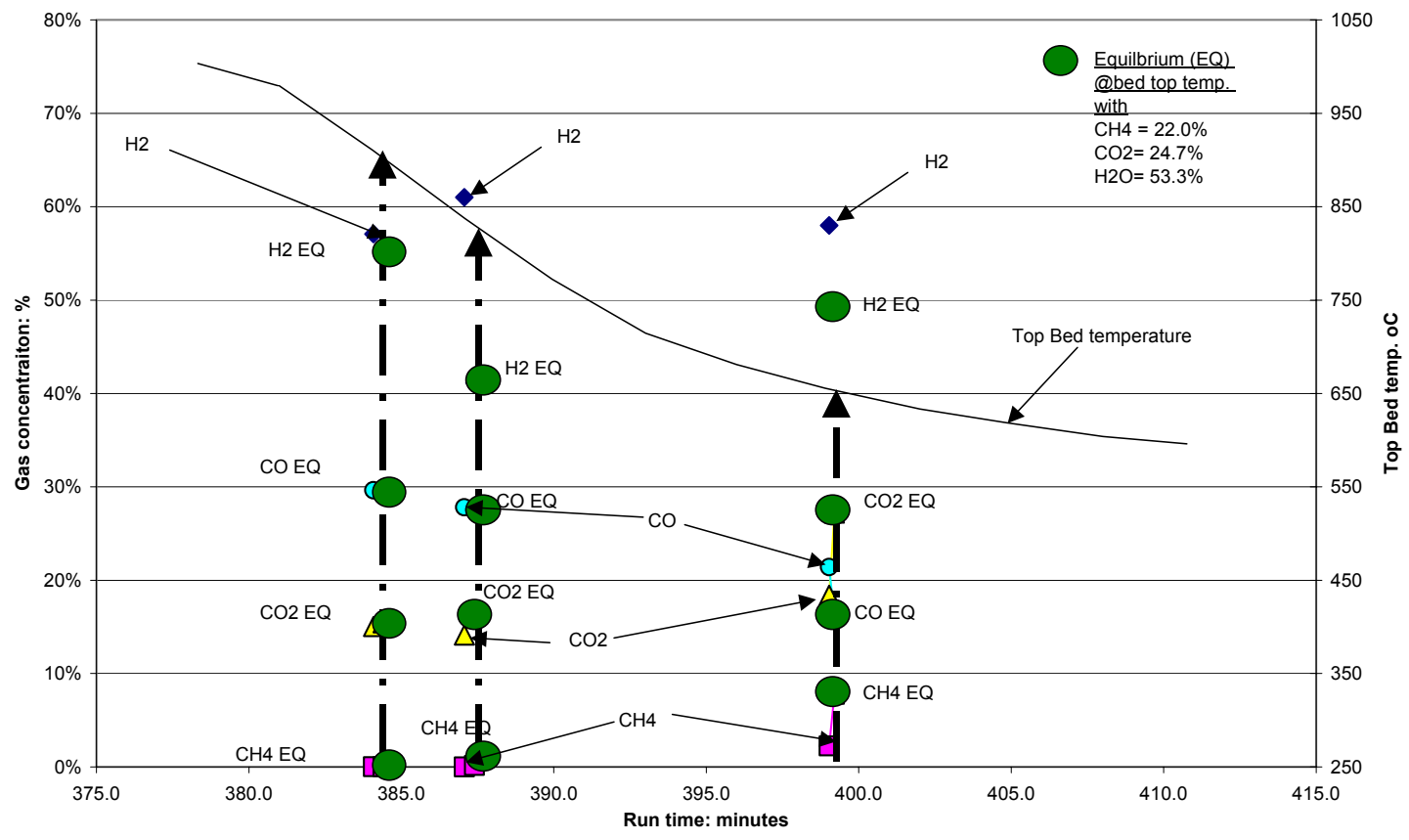

Figure 8. Equilibrium \& measured gas compositions (415-100-4-CH). 
(based on the GC data) at three different times. The reactor was slowing cooling due to the reforming, and the addition of heat from the tube furnace was not keeping up (the exit temperatures are not precisely known). Nevertheless, there is agreement with the measured gas compositions and the equilibrium values.

The 415-100-4-CH sorbent performed well under all operating conditions of the HOP. Oxidation removes $99 \%$ of the oxygen. Reforming converts the methane to $\mathrm{CO}$ and $\mathrm{H}_{2}$ without $\mathrm{CH}_{4}$ leakage, even when reforming lowers the sorbent temperature. This sorbent has the potential to meet our requirements for the HOP.

\subsubsection{Sorbent properties before and after cycling}

Table 3 presents the properties of the fresh and cycled sorbents, all of which have relatively low surface areas compared to traditional catalyst. However, these areas are measured in the oxide state. When the sorbents are reduced, the surface area increases as oxygen is removed for the lattice. The reforming occurs after the sorbent is reduced, which is probably why the reforming is very active (almost no methane remains in the reformed gases).

Table 3. Properties of fresh and cycled sorbents.

\begin{tabular}{|c|c|c|c|c|c|c|c|c|}
\hline Sorbent & Cycles & $\begin{array}{l}\text { Fresh } \\
\text { Crush } \\
\mathrm{lb} / \mathrm{mm}\end{array}$ & $\begin{array}{l}\text { Cycled } \\
\text { Crush } \\
\mathrm{lb} / \mathrm{mm}\end{array}$ & $\begin{array}{l}\text { Fresh } \\
\text { Void } \\
\text { cc/g }\end{array}$ & $\begin{array}{l}\text { Cycled } \\
\text { Void } \\
\text { cc/g }\end{array}$ & $\begin{array}{c}\text { Fresh } \\
\text { Surface } \\
\mathrm{m} 2 / \mathrm{g}\end{array}$ & $\begin{array}{c}\text { Cycled } \\
\text { Surface } \\
\mathrm{m} 2 / \mathrm{g}\end{array}$ & $\begin{array}{l}\text { Bulk } \\
\text { Density } \\
\text { g/cc }\end{array}$ \\
\hline $415-100-1$ & $0-21$ & 3.60 & 5.00 & 0.32 & 0.36 & 1.91 & 2.73 & 1.12 \\
\hline $415-100-1$ cont'd & $21-48$ & & 4.80 & & 0.31 & & 1.91 & 1.10 \\
\hline $415-100-2$ & 20 & \multicolumn{4}{|c|}{ Turned to powder in cycling } & & & \\
\hline $475-8$ & $0-27$ & 10.00 & 6.80 & 0.18 & 0.16 & $<0.03$ & 0.04 & 1.36 \\
\hline $415-100-4$ & $0-12$ & 5.00 & 7.30 & 0.19 & 0.18 & 2.13 & 1.50 & 1.51 \\
\hline
\end{tabular}

When cycled, sorbent sample 415-100-1-CH increased in strength from the fresh sorbent, and the strength and porosity remained stable during the cycling. After the first 21 cycles a second test was conducted for another 27 cycles, total of 48 cycles.

Sorbent sample 415-100-2-CL turned to powder during the cycling and is clearly not an acceptable sorbent for the HOP.

Sorbent sample 475-8 (remake of 415-100-3-CH) decreased in strength but remained strong, and was as strong as the other acceptable sorbents after cycling. One can see a level of scatter in the crush strength and porosity of the two batches of sorbent $475-8$ that is common in this type of measurement.

Sorbent sample 415-100-4-CH also increased in strength and retained its porosity with cycling.

Given the results of the breakthrough tests and the stability of the sorbent properties with cycling, TDA probably has three acceptable sorbents for the HOP:

1) $415-100-1-\mathrm{CH}$

2) $475-8(415-100-3-\mathrm{CH})$

3) $415-100-4-\mathrm{CH}$ 
TDA presented these results to DOE and after the review, DOE selected the 415-100-1-CH sorbent for multiple cycle testing, based on both the oxygen capacity, physical properties, the preferred oxygen capacity of the sorbent, and cost of the sorbent.

\subsection{Task 3: Multiple Cycle Testing}

TDA tested Sorbent $415-100-1-\mathrm{CH}$ for 1,506 hours ( 8,590 cycles). The objective of these experiments is to determine if there is any loss of oxygen capacity and/or reforming activity during the 1,500 hours of tests. All the gases leaving the reactor are cooled, allowing the water to condense separate, the gases are then vented.

The reactor pressure stays constant at 30 psig in all-operating modes. Neat air at a space velocity of 2,000 $\mathrm{h}^{-1}$ flows during the oxidation step of the cycle and only methane $\left(\mathrm{CH}_{4}\right)$ and steam $\left(\mathrm{H}_{2} \mathrm{O}\right)$ at a space velocity of $2,000 \mathrm{~h}^{-1}$ flow during the reforming step. Each cycle takes 10.34 minutes. To minimize problems with the pump during cycling, we maintain a constant flow of $\mathrm{H}_{2} \mathrm{O}$ into the reactor. The $\mathrm{H}_{2} \mathrm{O}$ is then condensed outside the reactor before any gas analysis (i.e., the data are reported on a "dry" basis).

We cycle the sorbent using computer-controlled equipment, which allows 24 hours per day and 7 days a week operation. Data on oxygen loading and reforming activity is collected once a day (nominally for 3 cycles).

Figure 9 shows the oxygen loading of Sorbent $415-100-1-\mathrm{CH}$ in the new apparatus. There is significant scatter in the oxygen loading data, due in part to the data reduction and/or operating procedures. To minimize the cost of gases in this long experiment and given the limited funding, we operated with a small reactor and the sample gas flow is almost all of the total gas flow. 


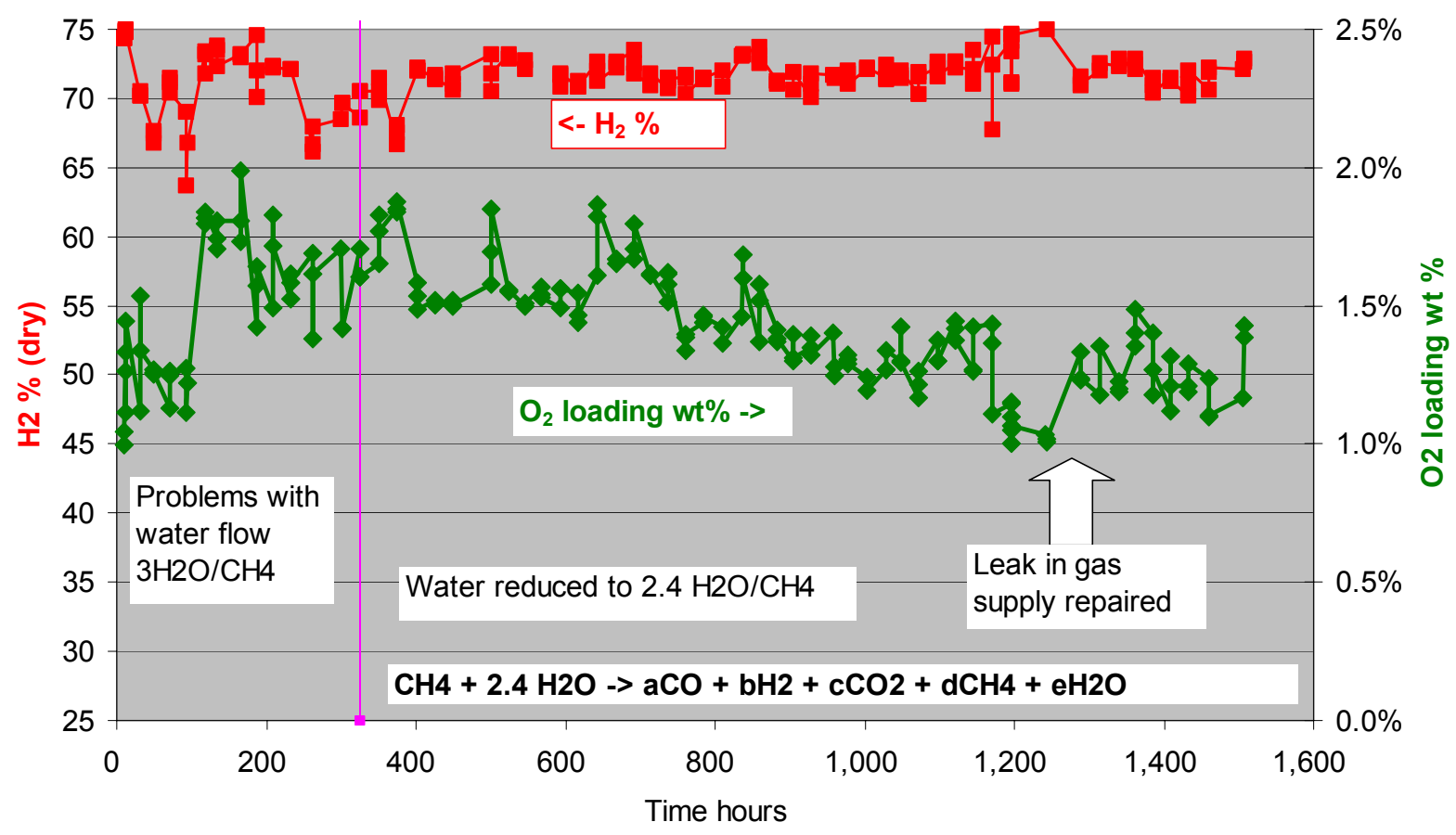

Figure 9. Multiple cycle testing of the sorbent.

Unfortunately, during the early cycling, we observed two problems with the water flow in the apparatus. One problem was that, periodically, the water flow would stop, leading to coking of the sorbent and overheating, and then the control system would shut down the apparatus. After several pump repairs, we were able to maintain constant water flow into the apparatus.

The second problem was poor mixing of the water vapor with the methane feed. This apparently kept some of the sorbent from being fully reduced, so we modified the apparatus (a new boiler and new point of mixing). Also, we lowered the steam to carbon ratio from 3:1 to 2.4:1 (since the new boiler was somewhat undersized), which stabilized the reactor operations. After 325 hours (1,835 cycles) all gas flows and water flows were the same for all subsequent cycles, and we proceeded to run the sorbent through 1,506 hours on 8,596 cycles.

At the end of the test, he sorbent was demonstrating stable oxygen loading and good reforming (Figure 9). Although the sorbent initially lost oxygen capacity the oxygen capacity stabilized after 1,000 hours of testing at $\sim 1.2 \%$ (wt) oxygen.

Figure 10 presents the composition of the gas leaving the reactor. Since the exhaust gases contain steam that makes analysis difficult, we condense the steam and then separate the water in a $500 \mathrm{cc}$ container. We also purge the reactor with nitrogen before flowing methane steam mixture, which fills the reactor and $500 \mathrm{cc}$ container with nitrogen. Due to the volume of the separating container, there is a time delay from when a gas flow starts and the gases reach the analyzers. In addition, it also takes time for the gas mixture to purge the separating container so that the outlet of the separating container is near the inlet gas composition.

Although methane flow started at time $=0$, there is about a one minute delay before the gases reach the analyzers. Initially some methane leaks though the reactor and after the nitrogen flow is stopped, 
the methane decreases and then increases as the reactor cools down during the endothermic reforming. After $\sim 3 \frac{1}{2}$ minutes after the start of methane flow, the hydrogen at the analyzers reaches the same level as the exhaust from the reactor. The maximum hydrogen value in any measured cycle is recorded as the hydrogen concentration reported in Figure 9.

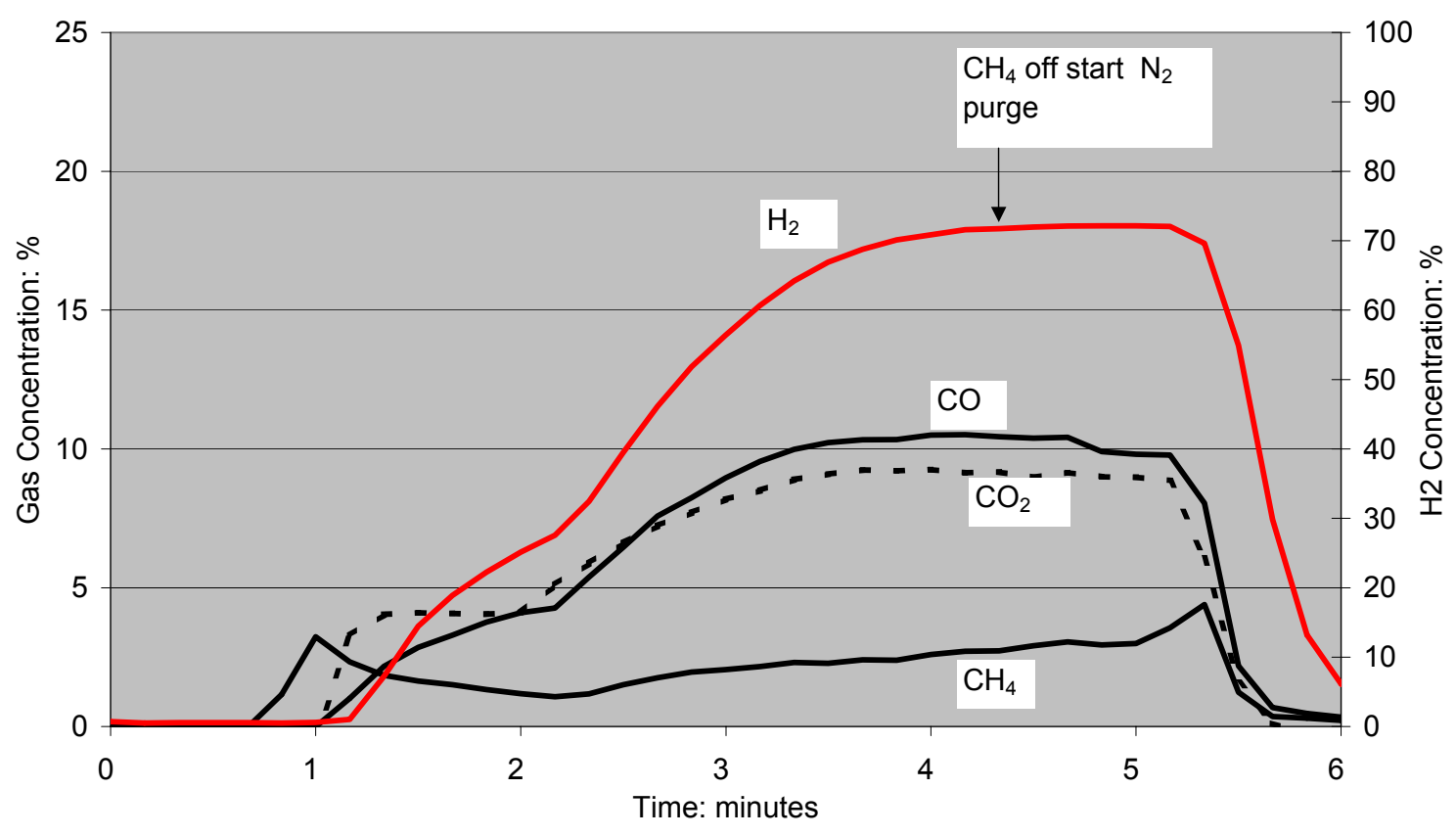

Figure 10. Typical reforming gas compositions.

TDA compared the measured hydrogen, carbon monoxide, carbon dioxide, and methane (dry basis) with that predicted for equilibrium at the measured outlet temperature in the reactor. The data indicated relatively good agreement in hydrogen, carbon monoxide and carbon dioxide. However, the methane concentration was lower than what is predicted for the pressure and temperature of the reactor. This may simply mean that the temperatures upstream in the reactor are higher and that the methanation reaction is slower than the other reactions (e.g., water gas shift).

\subsection{Task 4: Process Design and Assessment}

This portion of the work was conducted under co-funding by Air Products and Chemicals, Inc. Most of this data are EPAC protected and the details are provided as EPAC-protected information in Appendix A of this report.

\subsubsection{Reactor Thermal Modeling}

We prepared a simplified thermal model of the reactor, which allowed us to build it quickly and identify important design considerations. The key simplifying assumptions are outlined below:

1) The reactor is divided into multiple nodes.

2) The time step is set at the maximum for numerical stability.

3) The reducing gas and reforming gas flows are lumped together, and the net effect of reduction and reforming are added and applied at the same time.

4) All of the oxidation occurs in one node, in one time step. 
5) All of the reforming occurs in one node, in one time step.

6) The gas and solids are at the same temperature in a node/time step (i.e., no temperature differences due to heat transfer).

7) Inlet temperatures are constant.

8) The heat capacity is constant for both solids and gases.

9) Gas flows during reforming are nominal and not optimized.

10) Air flow rate during oxidation is nominal and not optimized.

11) Heat losses are assumed to be small.

12) Equilibrium concentrations are not modeled as a function of temperature.

13) The calculated temperatures at the end of a cycle are input as the starting temperatures of the next cycle, and then repeated until the inlet temperature of one cycle equals the temperatures of all the nodes at the end of the same cycle. In other words, the calculated temperature profiles are steady and no longer a function of cycling. Since the temperatures are always changing, but repeating in each cycle, we call this condition an "apparent steady state".

Figure 11 presents the reformed gas equilibrium for the gas-to-liquids with high $\mathrm{CO}_{2}$ recycle. In this case the gases show high levels of reforming (i.e., low methane concentrations) in the expected temperature range with either the co-flow or the counter flow reactor. We conclude that either co-flow or counter-current reactor types can be used effectively in this application.

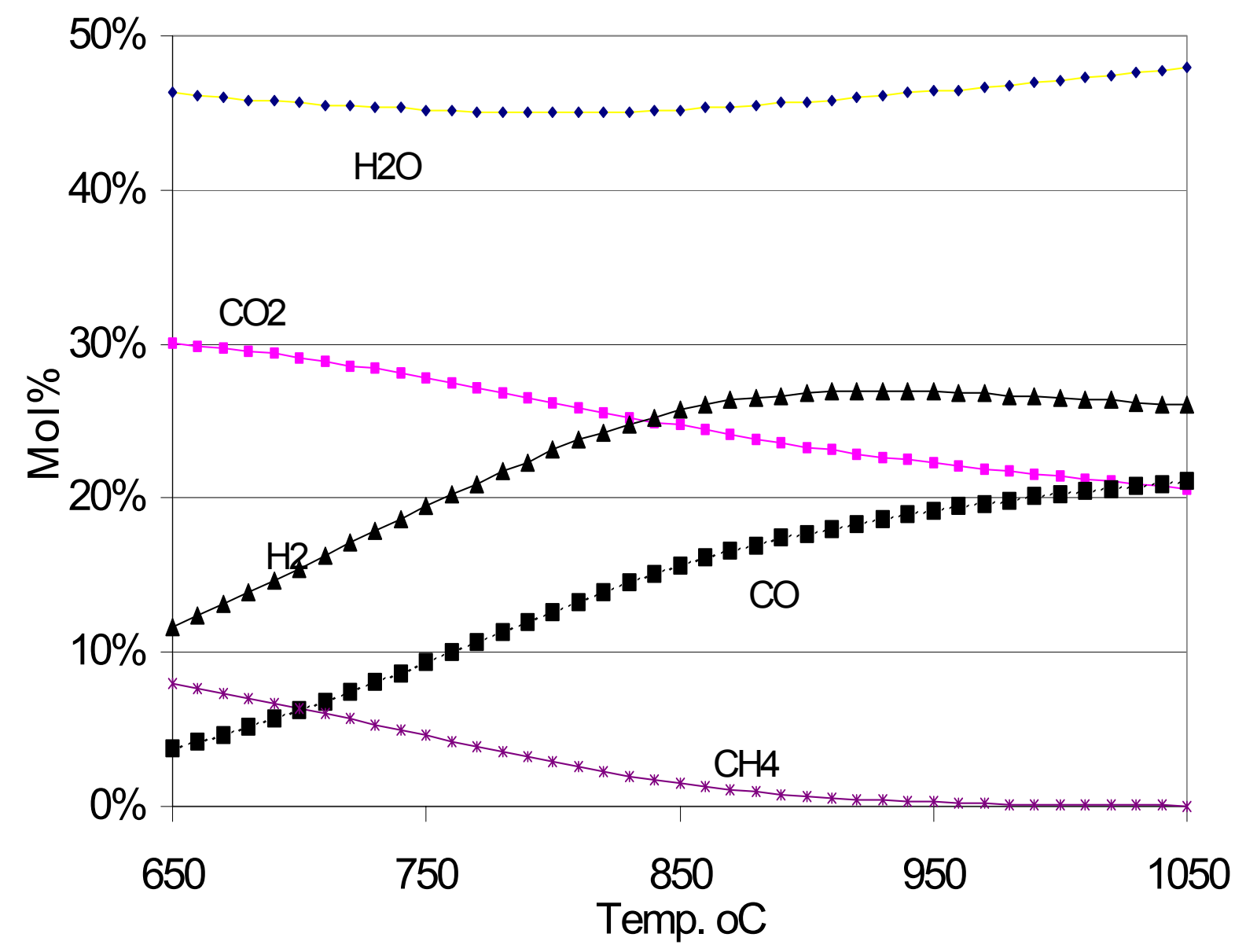

Figure 11. Reformed gas equilibrium for gas-to-liquids with high $\mathrm{CO}_{2}$ recycle. 


\section{Conclusions from the Modeling}

We have been able to draw several important conclusions based on this approximate model of the process as follows:

1) Either co-flow or counter-flow reactors can be used.

2) Co-flow and counter-flow reactors yield similar exit reforming gas temperatures and, therefore, compositions:

3 ) Both co-flow and counter-flow reactors effectively utilize the regenerative heat exchange

4) The net reaction is exothermic. This heat is removed from the reactor in the outlet vitiated air and the reformed gas flows and excess heat is removed by generating steam.

\subsubsection{Reactor Design}

TDA Research, Inc. prepared a design for the reactors required in the HOP. We size the plant for 50 MMSCFD of natural gas feed and calculated the steam and air flows for that plant size. We calculated the quantity of sorbent required, the pressure drop in the reactor, and the dimensions of the reactor (see Appendix A).

\subsection{HOP-Based GTL Plant}

Figure 12 illustrates the flows within the baseline HOP plant. Air is compressed and feed to the HOP Syngas unit, which produces a mixture of $\mathrm{CO}, \mathrm{H}_{2}, \mathrm{CO}_{2}, \mathrm{CH}_{4}$ and steam. The gases are cooled and the water condensed and the dry gas mixture enters the F-T process unit where 6,764 BPD of liquid fuel are produced. The F-T unit has internal recycle of gas (primary to remove the heat of reaction with addition mass flow through the F-T unit). Some of the gases produced in the F-T unit are recycled to the HOP Syngas unit to reform some of the methane which is made in the F-T process. The balance of the FT gas is burned to generate steam. 7.4 MMSCFD of additional natural gas is burned to generate steam for the process and to generate 22.6 MW of power required in the process. 


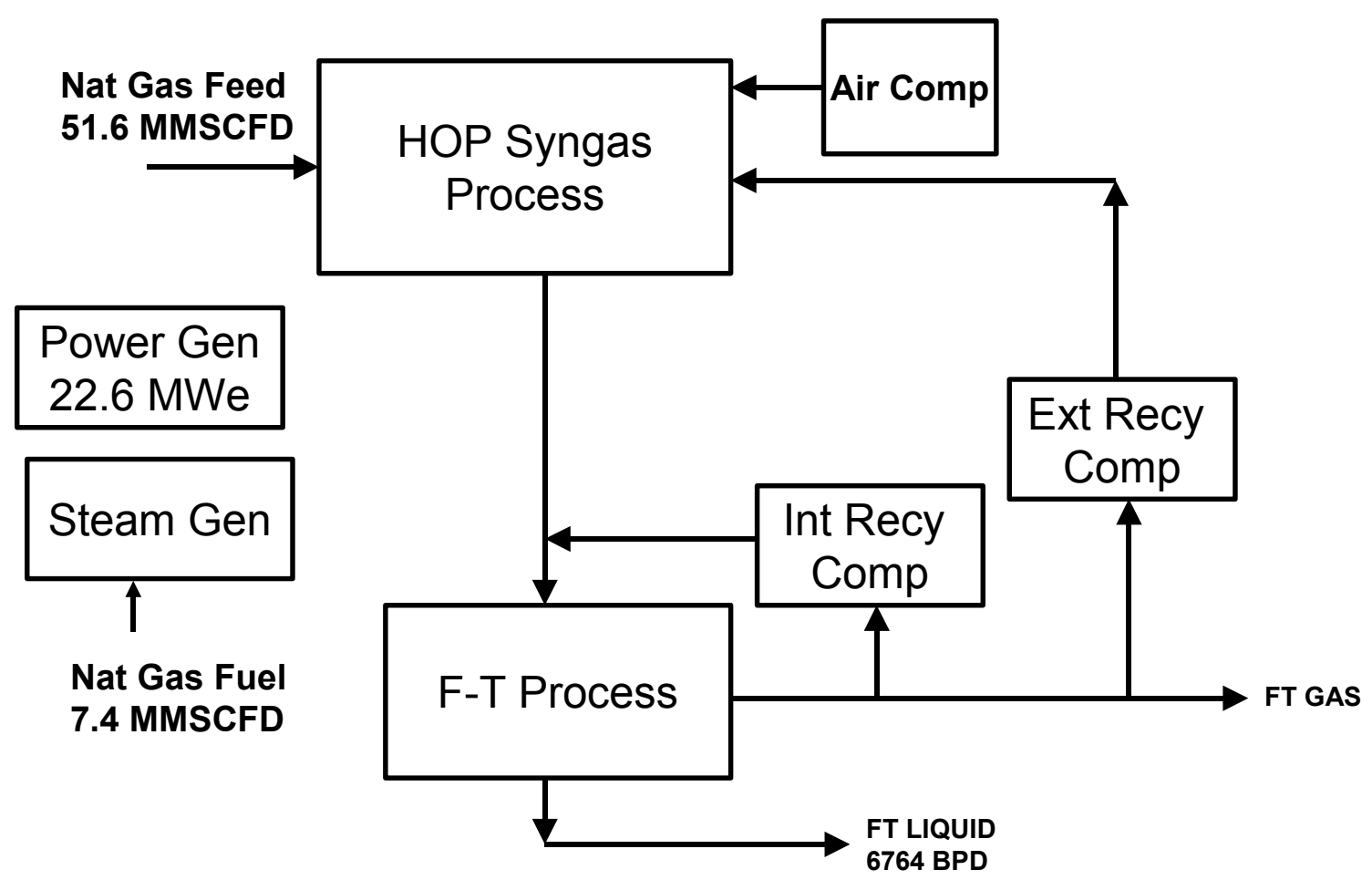

Figure 12. HOP-Based GTL Plant.

Although the HOP operates with fixed bed reactors, we model the HOP syngas generation as a continuous flow system. Air is compressed to 2 atm in the air compressor; due to pressure losses as the air flows through the plant, the vitiated air exits at ambient pressure. The compressed air is heat by recuperator \#2 (i.e., an inert pellet bed) and the hot air $\left(\sim 1,652^{\circ} \mathrm{F}\right.$, $900^{\circ} \mathrm{C}$ ) enters the HOP reactor where oxygen is transfer from the air. The hot vitiated air is cooled in recuperator \#1 and further cooled generating low pressure steam for the steam power plant.

We calculated preliminary capital cost and efficiency for the HOP and provide these data to APCl, who then conducted a detail ASPEN model of the plant and calculated costs for all the major components with their costing methodology.

\subsection{1. $\quad$ APCI GTL Modeling}

\section{Simulation Results}

APCI prepared a detailed ASPEN model of both the ATR and HOP processes. Table 4 presents the flows and other important considerations in the overall process. The model was set to use the same amount of natural gas (NG) feed, 51.6 MMSCFD. The steam requirements for the HOP are significantly higher, since TDA's tests indicated that the pre-reformed gas would form coke in the inert pellet beds is the steam to carbon ratio of the gas stream was less than 1.12. Since the pre-heating of the pre-reformed gases in the ATR case does not pre-heat the gases to as high a temperature, a steam to carbon ratio of 0.6 is allowable. 
Table 4. Comparison of Syngas Generation Processes.

\begin{tabular}{|l|c|c|}
\hline & ATR & HOP \\
\hline NG Feed & $51.6 \mathrm{MMSCFD}$ & $51.6 \mathrm{MMSCFD}$ \\
\hline Steam/Carbon & 0.6 & 1.12 \\
\hline Reforming Temp & $1832 \mathrm{~F}$ & $1742 \mathrm{~F}$ \\
\hline Ext FT Recycle & $1235 \mathrm{lbmol} / \mathrm{hr}$ & $4000 \mathrm{lbmol} / \mathrm{hr}$ \\
\hline SG Rate & $165 \mathrm{MMSCFD}$ & $198 \mathrm{MMSCFD}$ \\
\hline SG H2 + CO & $150 \mathrm{MMSCFD}$ & $169 \mathrm{MMSCFD}$ \\
\hline SG H2:CO & 2.03 & 2.03 \\
\hline SG to GTL & $63044 \mathrm{lbmol} / \mathrm{hr}$ & $63044 \mathrm{lbmol} / \mathrm{hr}$ \\
\hline H2:CO to GTL & 2.06 & 2.07 \\
\hline
\end{tabular}

Due to nature of the HOP reactors (see Appendix A.2 and there is more methane in the HOP gases than the ATR and consequently a higher external recycle of gases from the F-T unit to the syngas generation unit and a higher syngas (SG) flow, and a higher $\mathrm{H}_{2}$ and $\mathrm{CO}$ flow in the HOP. However the quality of the $S G$ (i.e., $\mathrm{H}_{2} / \mathrm{CO}$ ratio) is the same was well as the quantity of syngas flowing in the F-T unit.

Table 5 presents the overall feed flows for the ATR and HOP processes. For the same feed of natural gas to the reactors, the HOP requires more natural gas fuel to generate the higher steam required, consumes slightly more oxygen, and cooling water. However, the HOP requires much less power, requires some additional fuel to generate the higher steam requirements, and produces slightly more liquid fuel. 
Table 5. Overall Balance Comparison.

\begin{tabular}{|l|c|c|}
\hline & ATR & HOP \\
\hline NG Feed & $51.6 \mathrm{MMSCFD}$ & $51.6 \mathrm{MMSCFD}$ \\
\hline O2 Required & $4.1 \mathrm{MMSCFD}$ & $7.4 \mathrm{MMSCFD}$ \\
\hline Power Required & $34,040 \mathrm{KW}$ & $22,580 \mathrm{KW}$ \\
\hline Cooling Water & $85 \mathrm{M}-\mathrm{gpm}$ & $91 \mathrm{M}-\mathrm{gpm}$ \\
\hline FT Liquid Prod'n & $6,410 \mathrm{BPD}$ & $\begin{array}{c}6,764 \mathrm{BPD} \\
(5 \% \mathrm{More} \\
\text { than ATR) }\end{array}$ \\
\hline
\end{tabular}

\section{Basis for Economic Analysis}

Based on the ASPEN model APCI size all of the major components in the system and calculated the capital costs. Table 6 presents the total cost for each. Due to the lower power requirement and elimination of the ASU, the HOP capital costs are substantially lower than the ATR case $(37 \%)$, excluding the cost of the F-T synthesis plant and the hydrocarbon upgrading plant.

APCI had an existing ASPEN model of a Gas To Liquids (GTL) plant based on an autoTable 6. Capital Investment Comparison.

\begin{tabular}{|l|c|c|}
\hline & ATR & HOP \\
\hline Total Investment & $108 \mathrm{MM}$ & $67 \mathrm{MM}$ \\
Required & & (37\% Less \\
(US Gulf Coast & & than ATR) \\
$\$ 2000)$ & & \\
\hline
\end{tabular}

Total investment cost includes the Syngas Plant, F-T Recycle Compressor, Initial Catalyst Charge, Offsites/Utilities, Owner's Costs and Contingencies. The costs of the F-T Synthesis Plant and Hydrocarbon Upgrading Plant are not included. thermal reforming (i.e., oxygen injected into the natural gas steam mixture). APCl also had a detailed cost analysis for the conventional auto-thermal reforming plant.

APCI modified their previous ASPEN model to incorporate a HOP to supply the oxygen into the plant and removed the air separation features. APCl modified the flows in all of the plant with the same natural gas feed rate. Due to the elimination of the air separation plant, the power requirements were greatly reduced but other items increased (e.g., steam requirements). Using the same input of natural gas to the process, the HOP uses significantly less power and generates $5.5 \%$ more liquid product than the ATR.

Using TDA's reactor design and APCl's ASPEN model, APCI then estimated the costs of capital equipment, natural gas, replacement of parts, and operation. Based on the preliminary estimates for the non-optimized HOP, the cost of syngas when using the HOP was substantially lower than that of 
the ATR. The HOP's higher product liquid yield made the cost savings even higher. Clearly the HOP has potentially much lower costs than the ATR for GTL.

\section{Results of Economic Analysis}

Table 7 presents the annual cost for the ATR and the HOP process. The natural gas feed is the same for both cases but the natural gas used for fuel is higher with the HOP. Boiler feed water costs are essentially the same. Catalyst are higher with the HOP because of the larger sorbent bed, which is also the reforming catalyst. The Hydrogenation, Desulfurization and Pre-Reforming catalyst replacement were exactly the same for the ATR and HOP, the HOP sorbent and inert pellet replacement are the largest contributor to the catalyst costs. Labor costs are the same but maintenance is higher with the ATR. The largest cost and the biggest difference between the two processes is the capital cost, with the HOP clearly being preferred. The net cost is $17.2 \%$ lower annual cost with the HOP versus the ATR

Table 7. Cost Comparison on Annual Basis.

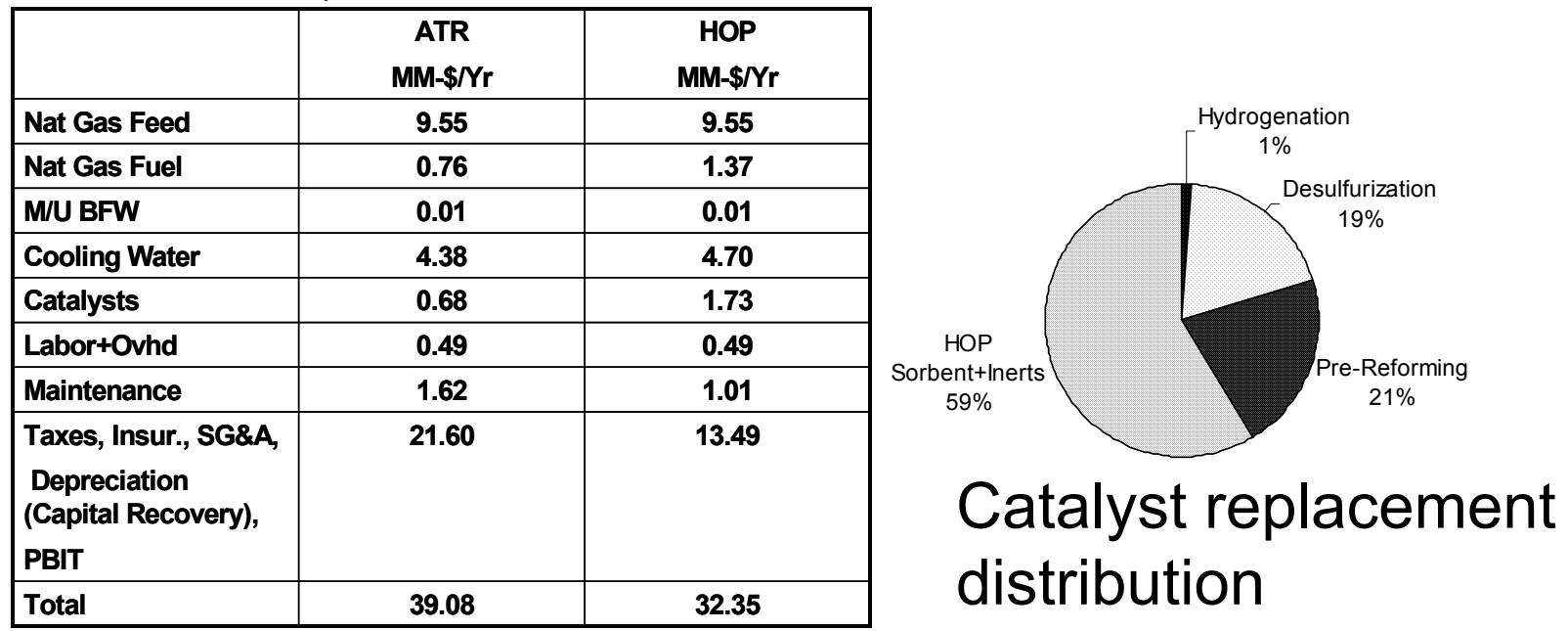

Table 8 presents the unit cost per barrel of liquid fuel produced. Because of the higher fuel production for the HOP, the natural gas costs are lower for exactly the same quantity of natural gas feed to the process. The net result is that with the $5 \%$ higher liquid fuel production, the HOP produces liquid fuel for $22 \%$ less than the ATR.
Table 8. Unit Cost Comparison.

\begin{tabular}{|l|c|c|}
\hline & $\begin{array}{l}\text { ATR } \\
\text { \$BL }\end{array}$ & $\begin{array}{c}\text { HOP } \\
\text { \$BL }\end{array}$ \\
\hline Nat Gas Feed & 4.17 & 3.95 \\
\hline Nat Gas Fuel & 0.33 & 0.57 \\
\hline M/U BFW & 0.004 & 0.004 \\
\hline Cooling Water & 1.91 & 1.94 \\
\hline Catalysts & 0.30 & 0.71 \\
\hline Labor+ Site Ovhd & 0.21 & 0.20 \\
\hline Maintenance & 0.71 & 0.42 \\
\hline $\begin{array}{l}\text { Taxes, Insur., SG\&A, } \\
\text { Depreciation } \\
\text { (Capital Recovery), } \\
\text { PBIT }\end{array}$ & 9.42 & 5.57 \\
\hline Total & & 13.37 \\
\end{tabular}




\section{Conclusions and Recommendations}

\subsection{Conclusions}

During this work we developed three sorbents, which can meet the requirements of the HOP. All three are active and chemically stable when cycled. In our small scale reactor, the reforming approaches equilibrium predicted for the test conditions.

We tested one sorbent for 1,500 hours. The oxygen capacity initially decreased with cycling, then stabilized after 1,000 hours and remained relatively constant thereafter. The reforming activity of our catalyst remained high in all cycles.

In comparison to a convention ATR with an air separation plant, with a single point design (i.e., not optimized plant design) the HOP has significant economic potential.

Although the HOP requires higher recycle $\left(\mathrm{CO}_{2}\right.$ from $\left.\mathrm{F}-\mathrm{T}\right)$, a Higher steam to carbon $(\mathrm{S} / \mathrm{C}=1.12$ vs. 0.6 for ATR), and operates with a lower reforming temp: $=950^{\circ} \mathrm{C}\left(1,742^{\circ} \mathrm{F}\right)$, the $\mathrm{HOP}$ process requires less capital than ATR-based process and produces more fuel $(5 \%)$

The capital estimate includes all steam generation, pre-treatment, recycle compressors, fired heaters, and power generation equipment but Excludes the F-T synthesis \& upgrading units in both cases.

Due to the high cost of the Air Separation Unit and the power to operate the ASU, the ATR process costs $\$ 17.05 / \mathrm{bl}$ of liquids versus HOP costs of $\$ 13.37 / \mathrm{bl}$ of liquids (22\% less).

\subsection{Recommendations}

In our small scale tests, we were able to test the sorbent for an extended time. However, we recommend testing in a large scale, truly adiabatic reactor. Since the process requires a very long life need, more cycling tests with durations of a year or more are recommended to determine the life and characteristics of the catalyst for times similar to those required for the sorbent to be economic.

Our system was based on a single point design, which has not been optimized. We recommend additional system studies to evaluate potentially more attractive design options.

On the positive side, both the ATR and HOP processes were compared on the same basis. Unfortunately, most analyses of ANS GTL technologies suffer from the same assumptions. Using a Gulf Coast basis for construction/installation for ANS applications provides the best of both worlds - cheap equipment/labor for the Gulf Coast, and cheap ANS gas. A more detailed economic analysis (i.e. sensitivity analysis) to explore the sensitivity of costs to geographic location is recommended. 